\title{
Características de la práctica pedagógica en el área de Química
}

\author{
Characteristics of pedagogical practice in the chemical area \\ Características da prática pedagógica na área química
}

Francisco Javier Blanchar-Añez ${ }^{10}$

Recibido: mayo de 2019

Aceptado: noviembre de 2019

Para citar este artículo: Blanchar-Añez, F. J. (2020). Características de la práctica pedagógica en el área de Química. Revista Científica, 37(1), 30-57. Doi: https://doi.org/10.14483/23448350.14855

\section{Resumen}

El presente artículo se deriva de la investigación realizada en la institución educativa oficial Centro de Integración Popular (IPC), del Distrito Turístico de Riohacha, Colombia, cuyo objetivo central fue el de analizar las competencias científicas desarrolladas en los estudiantes de a través de las características de la práctica pedagógica institucional en el área de Química. Aspectos establecidos alrededor de las directrices teóricas (pedagógicas y didácticas) establecidas en el sistema educativo colombiano por competencias. Dado el carácter integral de la investigación desarrollada, que abarcó el análisis del currículo oficial del establecimiento educativo, la identificación de las propiedades de las prácticas pedagógicas en el aula y el proceso de evaluación en el área de Química, se aplicaron diferentes técnicas metodológicas, tales como: el análisis documental para el primer y el tercer aspecto y la observación y registro descriptivo para el segundo. La investigación se enmarcó en el enfoque cuantitativo, siguiendo un diseño descriptivo, en el cual se trabajó con las unidades de análisis de 34 elementos documentales, 4 docentes y 523 estudiantes de la sede central de la institución oficial. Los resultados evidenciaron que esta institución educativa cuenta con un currículo oficial genérico basado en la concepción tradicional de la enseñanza y sus prácticas de aula del área de Química se caracterizan por la exposición magistral del docente en torno a los contenidos declarativos; además de la ausencia de actividades estimulantes de procesos cognitivos complejos y desafiantes para los alumnos en torno a aspectos procedimentales y actitudinales.

Palabras clave: competencias científicas, enseñanza y aprendizaje de la química, práctica pedagógica.

\begin{abstract}
This article is derived from the research carried out in the official Educational Institution Center of Popular Integration (IPC), of the Tourist District of Riohacha, Colombia, whose main objective was to analyze the scientific competences developed in the students through the characteristics of institutional pedagogical practice in the area of chemistry; aspects contemplated around the theoretical guidelines (pedagogical and didactic) established in the Colombian Educational System by competences. Given the integral character of the research developed, which included the analysis of the official curriculum of
\end{abstract}


the educational establishment, the identification of the properties of the pedagogical practices in the classroom and the evaluation process in the area of chemistry, different methodological techniques were implemented; such as the documentary analysis for the first and the third aspect and the observation and descriptive record for the second. The investigation was framed in the quantitative approach following a design of descriptive type, working with the units of analysis of 34 documentary elements, 4 teachers and 523 students of the central headquarters of the official institution. The results showed that this educational institution has a generic official curriculum based on the traditional conception of teaching, and its classroom practices in the area of chemistry are characterized by the master's exposition of the teacher around the declarative contents; besides the absence of stimulating activities of complex and challenging cognitive processes for the students around procedural and attitudinal aspects. Keywords: pedagogical practice, scientific competences, teaching and learning of chemistry.

\section{Resumo}

Este artigo é derivado da pesquisa realizada no Centro oficial Instituição acadêmica para a Integração Popular (IPC), na zona turística de Riohacha, Colômbia, cujo principal objetivo foi analisar as competências científicas desenvolvidas nos alunos através de características da prática pedagógica institucional na área da química; aspectos contemplados em torno das orientações teóricas (pedagógicas e didáticas) estabelecidas no Sistema Educativo colombiano por competências. Dada a natureza abrangente da pesquisa, realizada, que incluiu a análise do currículo oficial do estabelecimento de ensino, a identificação das propriedades de práticas de ensino no processo de avaliação na área da química sala de aula e, técnicas metodológicas diferentes foram implementadas; como a análise documental para o primeiro e o terceiro aspecto e a observação e registro descritivo para o segundo. A investigação foi enquadrada na abordagem quantitativa seguindo um delineamento de tipo descritivo, trabalhando com as unidades de análise de 34 elementos documentários, 4 professores e 523 alunos da sede central da instituição oficial. Os resultados mostraram que essa instituição de ensino possui um currículo oficial genérico baseado na concepção tradicional de ensino, e suas práticas de sala de aula na área da química caracterizam-se pela exposição do mestre ao professor em torno dos conteúdos declarativos; além da ausência de atividades estimulantes de processos cognitivos complexos e desafiadores para os estudantes em torno de aspectos procedimentais e atitudinais.

Palavras-chaves: prática pedagógica, competências científicas, ensino e aprendizagem de química.

\section{Introducción}

El mundo actual se caracteriza por una significativa influencia de la ciencia y la tecnología en el desarrollo de la sociedad y en la vida cotidiana de las personas que incide en ámbitos tan cruciales de nuestra existencia como el transporte, la democracia, las comunicaciones, la toma de decisiones, la alimentación, la medicina, el entretenimiento, las artes e inclusive, la educación, entre muchos más, los cuales están signados por los avances científicos y tecnológicos (Ministerio de Educación Nacional, 2006). En tal sentido, parece difícil que el ser humano logre comprender el mundo y desenvolverse en él sin una formación científica básica.

En relación con esta perspectiva mundial de evolución y constante cambio, se requiere que sus habitantes posean los conocimientos y herramientas necesarias, provistas por las ciencias, para poder comprender su entorno y aportar a su transformación. Y, además de tener en cuenta estos beneficios al desarrollo de la humanidad, también los diferentes impactos negativos y enormes desigualdades que estos han generado.

Esta formación en ciencias, y específicamente en el área de química, objetivo específico del presente trabajo, se encuentra relacionada con el hecho de contribuir a la consolidación de ciudadanos y ciudadanas capaces, tal como lo establece el Ministerio de Educación Nacional (MEN, 2006), de asombrarse, observar y analizar lo que acontece a su alrededor y en su propio ser; formularse 
preguntas, buscar explicaciones y recoger información; detenerse en sus hallazgos, analizarlos, establecer relaciones, hacerse nuevas preguntas y aventurar nuevas comprensiones. Y, sobre todo, de hacer uso ético de los conocimientos científicos, todo lo cual aplica por igual para fenómenos tanto naturales como sociales. Todos estos propósitos podrían lograrse en el ámbito educativo colombiano mediante la adquisición y desarrollo de las competencias científicas pertinentes.

Con el fin de contribuir al análisis didáctico y al aporte de la consolidación de una didáctica de las ciencias naturales, la presente investigación tiene como objetivo principal analizar las competencias científicas desarrolladas en los estudiantes de un establecimiento oficial en el departamento de La Guajira, Colombia: la institución educativa Centro de Integración Popular (IPC), del Distrito Turístico de Riohacha, a partir de las características de la práctica pedagógica del área de Química y las directrices teóricas (pedagógicas y didácticas) establecidas en el sistema educativo colombiano.

\section{La educación y su papel para el desarrollo de la sociedad}

La educación constituye un fenómeno multidimensional complejo en el que se promueve la formación y desarrollo intelectual de los individuos mediante el análisis, la enseñanza y el aprendizaje, así como la construcción de diversos conocimientos derivados de las distintas áreas del saber. La meta fundamental de los procesos educativos es la construcción de ciudadanía; es decir, la formación de individuos conscientes de su responsabilidad y compromiso con el desarrollo del grupo social al que pertenecen. En este sentido, existe un consenso histórico relacionado con la importancia de la educación como estandarte fundamental del desarrollo social. Tal como lo plantea la Comisión Internacional sobre la Educación para el siglo XXI en su informe a la Unesco al señalar que, frente a los numerosos desafíos del porvenir, la educación constituye un instrumento indispensable para que la humanidad pueda progresar hacia los ideales de paz, libertad y justicia social (Unesco, 1998).

Teniendo en cuenta el papel trascendental de la educación para la sociedad y la complejidad de los procesos subyacentes de los fenómenos educativos; toda nación debe procurar el diseño de sus sistemas educativos basados en entidades multidisciplinarias organizadas con base en lineamientos normativos y referentes teóricos propios de las diversas disciplinas que lo sustentan, de carácter pedagógico, curricular, legal normativo (pedagogía, didáctica, psicología, sociología, entre otras), amparadas en el consenso institucional nacional e internacional producto de la investigación y actualización didáctica y pedagógica.

En concordancia con la dinámica mundial actual, Colombia se apropia de esta tendencia y establece en cabeza del MEN (2008) el desarrollo de programas y proyectos interrelacionados hacia el mejoramiento de la calidad educativa, orientados al mejoramiento y fortalecimiento institucional para lograr los aprendizajes y el desarrollo de las competencias básicas, ciudadanas y laborales. Las cuales, a través del establecimiento de metas educativas basadas en la cobertura de todos los estudiantes independientemente de su procedencia, buscan ofrecer oportunidades para desarrollar las habilidades y valores necesarios para vivir, convivir, ser productivo y seguir aprendiendo a lo largo de la vida MEN (2008).

\section{La educación científica y su desarrollo a través de competencias en Colombia}

A través del sistema educativo basado en competencias en Colombia la Química se establece como una de las principales disciplinas en las ciencias naturales que permitiría contribuir a la consolidación de competencias científicas basadas en la comprensión, explicación y entendimiento de los principales fenómenos naturales y sociales que constituyen el entorno cotidiano de los seres humanos. Y, a su vez, consolidar la capacidad reflexiva y crítica de los sujetos para tomar decisiones 
apropiadas en torno al desarrollo económico, político, social, ambiental y ecológico de la sociedad (Tobón, Pimienta y García, 2010). En términos académicos, este proceso se manifiesta a través del desarrollo de conceptos, procedimientos y actitudes basadas en fundamentos de la ciencia, sustentadas en procesos formativos por competencias.

Una de las particularidades halladas se relaciona en los currículos oficiales (compendio de documentos de planificación educativa como los proyectos educativos institucionales [PEI] los planes de estudio o de área, planificadores de clase) es que incluyen de manera teórica y declarativa estas directrices. Pero, en la práctica real, el ejercicio pedagógico y didáctico puesto en marcha a través de los procesos formativos y evaluativos se realiza bajo las características de la educación tradicional, amparadas bajo modelos pedagógicos no pertinentes y descontextualizados, como la enseñanza y aprendizaje memorístico y repetitivo de la información; situación característica no solo en Colombia, si no en varias naciones latinoamericanas $y$ en el mundo.

A pesar de los modelos pedagógicos alternativos propuestos, tal como lo plantea Castillo (2011), la enseñanza de las ciencias se basa en la utilización del modelo tradicional, lo que acarrea un proceso instruccional reducido a una simple transmisión y recepción de conocimientos elaborados, propiciando en los estudiantes una actitud pasiva, dependiente y un aprendizaje memorístico de los contenidos discrepando entonces entre las orientaciones pedagógicas establecidas nacionalmente, formación por competencias basada en el enfoque constructivista, y los procesos educativos desarroIlados realmente. En este sentido, el MEN (1998), establece que varias investigaciones realizadas revelan que las posibles fallas de la evaluación por competencias son la carente comprensión teórica de este modelo y, por ende, fallas en su interpretación y aplicación efectiva.

El presente trabajo de investigación se basa en analizar los aspectos anteriormente descritos, centrando su estudio en la institución educativa
Centro de Integración Popular (IPC), ente de educación oficial localizada en el Distrito Turístico de Riohacha, capital del departamento de La Guajira; establecimiento público que no se aleja de esta realidad académica.

Esta institución educativa, de acuerdo con el Icfes (2015), obtuvo deficientes resultados en el área de Ciencias Naturales, principalmente en los niveles educativos de la básica secundaria y media. Por lo cual, se pretende analizar integralmente los procesos de diseño o planificación curricular, las prácticas pedagógicas y las características de los libros los textos utilizados como recursos en el área de Química en estos niveles educativos; con el objetivo principal de recopilar las diferentes pruebas sobre el desarrollo y adquisición de competencias científicas en los estudiantes en correlación con los lineamientos del proceso educativo por competencias del sistema educativo colombiano.

\section{Metodología}

El proceso de investigación se enmarcó en un enfoque cuantitativo, siguiendo un diseño descriptivo que, de acuerdo con Hernández, Fernández y Baptista (2010) se caracteriza porque la meta del investigador consiste en describir fenómenos, situaciones, contextos y eventos; esto es, detallar cómo son y cómo se manifiestan. Se aplicaron técnicas de investigación pertinentes basadas en el diseño de instrumentos de recolección de datos o información que contraste el tipo y diseño de investigación establecidos para cada uno de los aspectos previstos, los cuales se presentan a continuación:

- Análisis documental y de información: de acuerdo con Dulzaidez y Molina (2004), el análisis documental es una forma de investigación técnica, un conjunto de operaciones intelectuales que buscan describir y representar los documentos de forma unificada y facilitar su recuperación; que, complementado con el análisis de información, es una forma 
de investigación cuyo objetivo es la captación, evaluación, selección y síntesis de los mensajes subyacentes en el contenido de los documentos, a partir del análisis de sus significados, a la luz de un problema determinado.

- En referencia a esta técnica, en la investigación se aplicó un instrumento relacionados con la técnica de análisis documental y de información: 1) la lista de cotejo, basada en los lineamientos pedagógicos y didácticos establecidos a través del sistema educativo por competencias de Colombia, se pretenden analizar los aspectos de planificación y evaluación de la práctica pedagógica del área de química de la institución educativa de referencia (ver anexo 1).

- Observación: de acuerdo con Hernández et al. (2010) este método de recolección de datos consiste en el registro sistemático, válido y confiable de comportamientos y situaciones observables, mediante un conjunto de categorías y subcategorías. A través de la aplicación de un instrumento como la guía de observación y registro, sustentada a través de la propuesta de un instrumento de análisis de las prácticas educativas bajo el enfoque constructivista de Fernández Tuset, Ross, Leyva y Alvídrez (2010); aplicada al componente de desarrollo pedagógico y didáctico de la práctica pedagógica del área de Química (ver anexo 2).

En la tabla 1 se presentan las unidades de análisis previstas en el estudio.

En cuanto a las técnicas e instrumentos de recolección de información, de acuerdo con las características de los objetivos y propósitos de la investigación, se diseñó un plan para la selección de las técnicas de investigación pertinentes y la construcción de los instrumentos de recolección de datos o información que contrasten el tipo y diseño de investigación establecidos. Según Hernández et al. (2010), este plan se basó en la reevaluación de las variables de investigación, la literatura de sistemas de medición utilizados en investigaciones similares anteriores y los componentes, dimensiones o factores que integran a las variables.

Tabla 1. Unidades de análisis de la investigación.

\begin{tabular}{|c|c|c|c|c|}
\hline $\begin{array}{l}\text { Unidad de } \\
\text { análisis }\end{array}$ & Clasificación & Aspectos específicos & $\begin{array}{l}\text { Elementos de la } \\
\text { unidad }\end{array}$ & $\begin{array}{l}\text { Total de elementos } \\
\text { de análisis }\end{array}$ \\
\hline \multirow{4}{*}{ Documentos } & \multirow{2}{*}{$\begin{array}{l}\text { Documentos del } \\
\text { currículo institucional. }\end{array}$} & Proyecto Educativo institucional (PEI). & 1 & \multirow{4}{*}{$\begin{array}{l}4 \text { elementos } \\
\text { documentales }\end{array}$} \\
\hline & & $\begin{array}{l}\text { Sistema institucional de evaluación de } \\
\text { los estudiantes (SIEE). }\end{array}$ & 1 & \\
\hline & \multirow{2}{*}{$\begin{array}{l}\text { Documentos } \\
\text { específicos del área } \\
\text { de Química. }\end{array}$} & $\begin{array}{l}\text { Plan de área de Ciencias Naturales y } \\
\text { Educación Ambiental (área de Química). }\end{array}$ & 1 & \\
\hline & & Plan de clases de Química. & 1 & \\
\hline \multirow{2}{*}{ Docentes } & \multirow{2}{*}{$\begin{array}{l}\text { Docentes del área de } \\
\text { Química. }\end{array}$} & $\begin{array}{l}\text { Docentes de los grados de educación } \\
\text { básica secundaria. }\end{array}$ & 3 & \multirow{2}{*}{4 docentes } \\
\hline & & $\begin{array}{l}\text { Docentes de los grados de educación } \\
\text { media. }\end{array}$ & 1 & \\
\hline \multirow[b]{2}{*}{ Estudiantes } & \multirow{2}{*}{$\begin{array}{l}\text { Estudiantes de } \\
\text { educación básica } \\
\text { secundaria y media } \\
\text { de las prácticas } \\
\text { pedagógicas de } \\
\text { Química. }\end{array}$} & $\begin{array}{l}\text { Estudiantes de educación básica } \\
\text { secundaria. }\end{array}$ & 433 & \multirow[b]{2}{*}{523 estudiantes } \\
\hline & & Estudiantes de educación media. & 90 & \\
\hline
\end{tabular}

Fuente: elaboración propia. 


\section{Resultados}

El análisis de la práctica pedagógica se desarrolló de manera integral, garantizando el estudio general y particular de aquellos elementos pedagógicos y didácticos relacionados con los procesos de enseñanza y aprendizaje de la Química en la institución educativa abarcando dos sistemas de referencia: 1) la estructura documental en dos magnitudes: la general institucional (características de los documentos que constituyen el currículo oficial institucional y que representan el discurso oficial: PEI) y el Sistema Institucional de Evaluación de los Estudiantes (SIEE) y la específica del área de Química (relacionada con aquel currículo oficial característico del área de Química —plan de área y plan de clase-) y 2) las características operacionales del currículo oficial manifestadas en el desarrollo de las prácticas de aula del área de Química.

\section{Componentes de diseño y planificación}

El componente de planificación fue estudiado en dos escalas: 1) a nivel institucional y 2) a nivel particular del área de Química. Para ambos aspectos el análisis se sustenta el establecimiento de un indicador cuantitativo que da cuenta del nivel de apropiación de los lineamientos del sistema educativo por competencias colombiano y el análisis cualitativo derivado de dicha cuantificación.

\section{Diseño y planificación institucional}

A nivel institucional, el documento representativo del diseño y planificación curricular institucional lo constituye $\mathrm{PEI}$, documento a partir del cual se desarrolló el análisis de tres aspectos normativos de referencia: 1) los aspectos estructurales que debe poseer cada PEI de acuerdo con el decreto 1860 de 1994, 2) los criterios pedagógico-didácticos generales establecidos como criterios de elegibilidad (meta del proceso educativo, secuencia pedagógica del proceso de formación, contenidos curriculares, relación maestro- alumno y estrategias didácticas) por Flórez (2005) y 3) Aspectos particulares de la formación en competencias científicas en ciencias explícitos en los Lineamientos Curriculares y Estándares Básicos de competencia de Ciencias Naturales y Educación Ambiental formulados por el MEN (1998 y 2004), respectivamente.

En la tabla 2 se relacionan los aspectos generales del análisis del componente de diseño y planificación institucional del PEI y los resultados establecidos para cada indicador.

\section{Diseño y planificación específica del área de Química}

A través de este componente se realizó el análisis de dos documentos relacionados con el diseño y planificación del área de Química: 1) el plan de área de Ciencias Naturales y Educación Ambiental de los niveles de educación básica y media y 2) el plan de clases, documentos formulados para el año lectivo 2015.

\section{Plan de área}

De acuerdo con la información relacionada con el estudio del plan de área se establecieron cuatro aspectos de análisis: 1) general: pedagógico-didáctico; 2) particular: competencias científicas; 3) diseño y planificación; 4) evaluación.

De acuerdo con los resultados obtenidos (tabla 3) se denotan una serie de fortalezas (aspectos presentes) y aspectos deficientes (aspectos ausentes) para cada elemento. Aquel que registró las mejores características regulares y satisfactorias de acuerdo con su ICob corresponde al diseño y planificación (4/7), mientras que los demás aspectos general: pedagógico didáctico (2/5), particular: competencias científicas (1/3) y evaluación (1/5), presentan índices deficientes representados por valores menores en su índice de cobertura. 
Tabla 2. Indicadores cuantitativos del componente de diseño y planificación institucional: PEl.

\begin{tabular}{|c|c|c|}
\hline \multicolumn{3}{|c|}{ Aspectos generales del documento } \\
\hline Documento & \multicolumn{2}{|c|}{ PEI de la institución educativa Centro de Integración Popular } \\
\hline $\begin{array}{l}\text { Referentes normativos del sistema } \\
\text { educativo colombiano aplicables al } \\
\text { documento }\end{array}$ & \multicolumn{2}{|c|}{$\begin{array}{l}\text { Decreto } 1860 \text { de } 1994 \text {. Por el cual se reglamenta parcialmente la ley } 115 \text { de 1994, } \\
\text { en los aspectos pedagógicos y organizativos generales. }\end{array}$} \\
\hline \multicolumn{3}{|c|}{ Aspectos de valoración cuantitativa y cualitativa } \\
\hline Aspecto & Indicador & Valoración cualitativa \\
\hline 1. Aspectos estructurales & ICob: 11/11 & $\begin{array}{l}\text { Criterios presentes } \\
\text { EIPEI incluye todos los aspectos requeridos para su formulación } \\
\text { de acuerdo con la normatividad vigente relacionada; } \\
\text { estos aspectos estructurales deben ser adaptados a cada } \\
\text { establecimiento y dependen de las propiedades educativas } \\
\text { establecidas por el consenso de la comunidad educativa. } \\
\text { Criterios ausentes. } \\
\text { Ninguno }\end{array}$ \\
\hline 2. Criterios pedagógico-didácticos & ICob: $2 / 5$ & $\begin{array}{l}\text { Criterios Presentes } \\
\text { En el PEI se discriminan dos de los cinco aspectos } \\
\text { relacionados: 1) la meta o el concepto del ser humano que ese } \\
\text { pretende formar y 2) se formulan una serie de consideraciones } \\
\text { pedagógicas generales del proceso formativo sin establecer } \\
\text { características específicas para los procesos pedagógicos. } \\
\text { Criterios ausentes } \\
\text { No se hace alusión a los otros tres criterios: } 3 \text { ) las experiencias } \\
\text { educativas privilegiadas, 4) la regulación entre los sujetos } \\
\text { directos del proceso educativo: relación maestro-alumno y 4) } \\
\text { el modelo de acción eficaz: métodos y técnicas de enseñanza } \\
\text { privilegiados. }\end{array}$ \\
\hline $\begin{array}{l}\text { 3. Aspectos particulares de la formación } \\
\text { en competencias científicas }\end{array}$ & ICob: $1 / 3$ & $\begin{array}{l}\text { Criterios presentes } \\
\text { En la misión institucional del PEI se incluye la expresión: } \\
\text { "la formación de una conciencia ecológica, la construcción } \\
\text { del conocimiento científico que posibilite el desarrollo de } \\
\text { competencias", deduciendo que este documento cumple } \\
\text { con el criterio de que 1) las actividades de enseñanza y } \\
\text { aprendizaje de contenidos científicos se relacionan de manera } \\
\text { clara y precisa. } \\
\text { Criterios ausentes } \\
\text { Los aspectos de 2) justificación de la formación en el ámbito } \\
\text { científico y 3) la identificación de competencias científicas. }\end{array}$ \\
\hline
\end{tabular}

Fuente: elaboración propia. 
Tabla 3. Indicadores cuantitativos y valoración cualitativa del componente de diseño y planificación especifica del área de Química: plan de área.

\begin{tabular}{|c|c|c|}
\hline \multicolumn{3}{|r|}{ Aspectos generales del documento } \\
\hline Documento & \multicolumn{2}{|r|}{ Plan de área de Ciencias Naturales y Educación Ambiental de los niveles de educación básica y media. } \\
\hline $\begin{array}{l}\text { Referentes } \\
\text { normativos del } \\
\text { sistema educativo } \\
\text { colombiano }\end{array}$ & \multicolumn{2}{|r|}{$\begin{array}{l}\text { Lineamientos Curriculares y Estándares Básicos de Competencia de Ciencias Naturales y Educación } \\
\text { Ambiental del MEN. }\end{array}$} \\
\hline \multicolumn{3}{|r|}{ Aspectos de valoración cuantitativa y cualitativa } \\
\hline Aspecto & Indicador & Valoración cualitativa \\
\hline $\begin{array}{l}\text { 1. General: } \\
\text { pedagógico-didáctico }\end{array}$ & ICob: $2 / 5$ & $\begin{array}{l}\text { Criterios presentes. En el documento se relacionan } 2 \text { de los } 5 \text { criterios de análisis: 1) la meta del } \\
\text { proceso educativo al manifestar el hecho de "propender por la formación integral de los estu- } \\
\text { diantes de la básica secundaria y media para que, apropiándose de los saberes dentro del área } \\
\text { apliquen sus conocimientos en el planteamiento de alternativas de solución a los problemas } \\
\text { dentro de su contexto", sociocultural y 2) las características del proceso de formación al rela- } \\
\text { cionar el "desarrollo de varios componentes especiales: aprender a aprender, aprender a desa- } \\
\text { prender, pero sobre todo, aprender haciendo, aprender a aplicar los conocimientos adquiridos } \\
\text { en la solución de los problemas cotidianos y de la comunidad de la cual él hace parte". } \\
\text { Criterios ausentes. No se hace alusión clara y directa a 3) las experiencias educativas privi- } \\
\text { legiadas (contenidos curriculares), 4) la regulación entre los sujetos directos del proceso edu- } \\
\text { cativo: relación maestro-alumno y 5) el modelo de acción eficaces: métodos y técnicas de } \\
\text { enseñanza. }\end{array}$ \\
\hline $\begin{array}{l}\text { 2. Particular: } \\
\text { competencias } \\
\text { científicas }\end{array}$ & ICob: $1 / 3$ & $\begin{array}{l}\text { Criterios presentes. Se identifican de manera clara en el plan de área: 1) las competencias } \\
\text { científicas como elementos importantes para la educación integral. } \\
\text { Criterios ausentes. No se evidencian la descripción de: 2) las actividades de enseñanza y } \\
\text { aprendizaje de contenidos científicos o 3) la importancia y justificación de la formación en el } \\
\text { ámbito científico a través del desarrollo por competencias. }\end{array}$ \\
\hline $\begin{array}{l}\text { 3. Diseño y } \\
\text { planificación }\end{array}$ & ICob: $4 / 7$ & $\begin{array}{l}\text { Criterios presentes. El documento analizado relaciona detalladamente los siguientes aspec- } \\
\text { tos: 1) una serie de competencias científicas en la propuesta curricular, estas se relacionan } \\
\text { de forma general con los contenidos, replicando cada una de ellas en cada contenido, hace } \\
\text { alusión a que: 2) la secuencia didáctica corresponde a la naturaleza de la enseñanza de las } \\
\text { ciencias, replicando la organización de los libros de texto de referencia, 3) se relacionan una } \\
\text { serie de competencias que no corresponden a la propuesta curricular del MEN para el área; } \\
\text { estas se relacionan de forma general con los contenidos, replicando cada una de ellas en cada } \\
\text { contenido. Las competencias relacionadas son: la competencia cognitiva, personales, inter- } \\
\text { personales intelectuales, investigativas, organizacionales y tecnológicas y 4) Se relacionan } \\
\text { recursos y yerramientas didácticas como texto guía, internet, aula inteligente, tablero, marca- } \\
\text { dores, biblioteca, laboratorio, revistas científicas, periódico, entre otros. } \\
\text { Criterios ausentes. En el documento no se hace alusión a los aspectos de: 5) relación de los } \\
\text { lineamientos curriculares y pedagógicos establecidos por el MEN acordes al grado y nivel } \\
\text { educativo relacionado, 6) inclusión de directrices en relación con el modelo pedagógico, } \\
\text { estrategias o recursos didácticos pertinentes a la meta de formación de los estudiantes y 7) lá } \\
\text { descripción de manera clara y concisa lineamientos relacionados con la enseñanza y el apre- } \\
\text { ndizaje de contenidos de las ciencias (química) acordes al nivel cognitivo de los estudiantes. }\end{array}$ \\
\hline 4. Evaluación & ICob: $1 / 5$ & $\begin{array}{l}\text { Criterios Presentes. Se explicitan las 1) actividades generales de carácter evaluativo relacio- } \\
\text { nadas con la evaluación en el área como lecturas y análisis de textos relacionados con las } \\
\text { temáticas propuestas, consultas bibliográficas, responsabilidad en la presentación de los tra- } \\
\text { bajos, participación de los estudiantes en las exposiciones o sustentaciones de los trabajos re- } \\
\text { alizados, elaboración de escritos y ensayos, organización, estética y orden en la presentación } \\
\text { de sus trabajos académicos y tolerancia y le respeto hacia los demás compañeros. } \\
\text { Criterios ausentes. 2) No se plantean actividades evaluativas en torno a las competencias bási- } \\
\text { cas y el desarrollo de habilidades cognitivas tal como se establecen en los estándares básicos } \\
\text { de competencia relacionados, 3) no se relacionan los contenidos en ciencias (científicos) en } \\
\text { las actividades evaluativas de los estudiantes, 4) el proceso evaluativo no se discrimina a través } \\
\text { de actividades continuas de seguimiento y evolución cognitiva de acuerdo con los estándares } \\
\text { básicos de competencia en Ciencias Naturales y 5) las actividades evaluativas en Química no } \\
\text { discriminan el tipo de competencia científica a evaluar. }\end{array}$ \\
\hline
\end{tabular}

Fuente: elaboración propia. 
Entre las principales fortalezas evidenciadas en este documento se encuentra que a nivel pedagógico y didáctico relaciona la meta del proceso educativo; además, se presenta la descripción de las principales características del proceso de formación en función de procesos como aprender a aprender, aprender a desaprender, pero, sobre todo, aprender haciendo y aprender a aplicar los conocimientos adquiridos en la solución de los problemas cotidianos. Según el aspecto particular: competencias científicas, el documento precisa la importancia de estas competencias como elementos importantes para la educación integral.

\section{Plan de clases}

Para el análisis del plan de clase se establecieron 9 aspectos de análisis, a partir de su estudio conjunto se estableció un ICob de 4/9; se evidencian fortalezas documentales relacionadas con la formulación de las pautas básicas de competencia en función de la guía de estándares básicos para el área y el grado respectivo establecida por el MEN para esta área del conocimiento. Los contenidos curriculares (unidad y temas) son pertinentes para el nivel y grado educativo respectivo; estos se presentan en secuencia lógica y coherente en concordancia con el orden lógico del área y los recursos didácticos relacionados son pertinentes para el tipo de actividad didáctica y el desarrollo de competencias científicas.

En la tabla 4 se detallan las características de los ICob para cada aspecto documental del plan de clases y la respectiva valoración cualitativa de los criterios presentes y ausentes para cada aspecto de diseño y planificación específica del área de Química.

Se evidenció la ausencia de las competencias científicas especificas del área de Química susceptibles de ser desarrolladas, además de dificultades para relacionar de manera puntual las estrategias de activación y exploración de los conocimientos previos de los estudiantes, de estrategias didácticas de enseñanza, actividades evaluativas para la verificación del éxito del proceso de enseñanza y aprendizaje y para determinar el desarrollo de habilidades cognitivas en los estudiantes.

\section{Componente de desarrollo pedagógico y didácti- co en las prácticas de aula}

El análisis del componente de desarrollo pedagógico-didáctico destaca las principales características de las prácticas de aula desarrolladas por cuatro docentes que imparten la asignatura de Química en el establecimiento educativo de referencia; producto de las observaciones de aula realizadas a través del instrumento de investigación puesto en marcha (dos observaciones por cada docente, para un total de ocho observaciones en total).

Los aspectos de observación se presentan organizados de acuerdo los nueve pasos discriminados en el instrumento de investigación. Cada paso y sus aspectos de análisis se presentan en una tabla independiente para facilitar su análisis, complementado de manera preliminar con una síntesis de cada uno de ellos. Los aspectos de análisis en cada tabla relacionada se organizaron de acuerdo con el porcentaje de evidencia, es decir, la frecuencia del aspecto de análisis en cada práctica pedagógica para facilitar la descripción y detalle de las variables pedagógicas y didácticas de interés.

En la tabla 5 se presenta los aspectos relacionados con el paso uno del instrumento, el cual se basó en la identificación del tipo de actividades educativas generales que plantea el maestro, numerarlas secuencialmente e indicar la duración.

Se puede evidenciar que en el $100 \%$ de las prácticas observadas (las 8 clases) se evidenció el predominio de aspectos como la práctica magistral a través de la exposición del maestro (aspecto 1.1), complementada esta exposición con preguntas a los alumnos (1.2), contestadas de forma escrita u oral (1.7), los cuales constituyeron los aspectos priorizados en cada una de ellas, evidencias que denotan características de clases magistrales, conductuales; en seguida, el desarrollo 
Tabla 4. Indicadores cuantitativos y valoración cualitativa del componente de diseño y planificación específica del área de Química: plan de clase.

\begin{tabular}{|c|c|c|c|}
\hline Documento & \multicolumn{3}{|c|}{ Plan de Clase de química de los niveles de educación básica y media } \\
\hline $\begin{array}{l}\text { Referentes normativos del sistema } \\
\text { educativo colombiano aplicables al } \\
\text { documento }\end{array}$ & \multicolumn{3}{|c|}{$\begin{array}{l}\text { Decreto } 230 \text { de } 2012 \text { del MEN. } \\
\text { Orientaciones pedagógicas establecidas a través de la red de conocimiento Colombia } \\
\text { Aprende MEN (2007). }\end{array}$} \\
\hline \multicolumn{2}{|l|}{ Aspecto de análisis } & & Descripción \\
\hline \multicolumn{2}{|c|}{$\begin{array}{l}\text { 1. Se relacionan las competencias científicas del área } \\
\text { susceptibles de ser desarrolladas. }\end{array}$} & \multirow{9}{*}{\begin{tabular}{|l}
$\mid$ \\
ICob: $4 / 9$
\end{tabular}} & \multirow{9}{*}{$\begin{array}{l}\text { Criterios presentes. 1) los estándares planteados } \\
\text { corresponden a los establecidos en la guía del MEN } \\
\text { (2006) para el área de Ciencias Naturales, 2) los } \\
\text { contenidos curriculares establecidos corresponden } \\
\text { a la organización temática de los libros de texto de } \\
\text { referencia para cada uno de los niveles y grados } \\
\text { educativos del sistema educativo colombiano, 3) } \\
\text { los contenidos presentan la secuencia lógica del } \\
\text { área de acuerdo con la propuesta de secuencia } \\
\text { didáctica del MEN (1998), y 4) los recursos y } \\
\text { herramientas didácticas relacionadas corresponden } \\
\text { a elementos de uso pedagógico general como texto } \\
\text { guía, internet, aula inteligente, tablero, marcadores, } \\
\text { biblioteca, laboratorio, revistas científicas, } \\
\text { periódico, entre otros. } \\
\text { Criterios ausentes } \\
\text { 5) No se hace relación explícita de las competencias } \\
\text { del área de Química a desarrollar en los estudiantes, } \\
\text { 6) el diseño documental del plan de clase no prevé } \\
\text { la inclusión de estrategias ni actividades para la } \\
\text { activación y exploración de conocimientos previos } \\
\text { de los estudiantes, 7) no se aclaran estrategias o } \\
\text { actividades didácticas específicas, 8) las actividades } \\
\text { evaluativas establecidas son de carácter genérico, } \\
\text { no se establecen actividades específicas en relación } \\
\text { con contenidos temáticos y 9) no se establecen } \\
\text { acciones pedagógicas de seguimiento o evolución } \\
\text { de aprendizajes en torno a las competencias o } \\
\text { habilidades cognitivas. }\end{array}$} \\
\hline $\begin{array}{l}\text { 2. Los estándares de competencia } \\
\text { pertinentes con los preestablecidos } \\
\text { estándares básicos para el área y el gra }\end{array}$ & $\begin{array}{l}\text { lacionados son } \\
\text { en la guía de } \\
\text { respectivo. }\end{array}$ & & \\
\hline $\begin{array}{l}\text { 3. Se establece de manera clara y p } \\
\text { de activación y exploración de los cc } \\
\text { de los estudiantes. }\end{array}$ & $\begin{array}{l}\text { las estrategias } \\
\text { nientos previos }\end{array}$ & & \\
\hline $\begin{array}{l}\text { 4. Los contenidos curriculares (un } \\
\text { pertinentes para el nivel y grado edu } \\
\text { acuerdo con los estándares básicos d }\end{array}$ & $\begin{array}{l}\text { y temas) son } \\
\text { o respectivo de } \\
\text { mpetencia. }\end{array}$ & & \\
\hline $\begin{array}{l}\text { 5. Los contenidos } \\
\text { lógica y coherent } \\
\text { del área. }\end{array}$ & & & \\
\hline $\begin{array}{l}\text { 6. Los recursos didácticos relacionad } \\
\text { para el tipo de actividad didáctica } \\
\text { competencias científicas. }\end{array}$ & $\begin{array}{l}\text { son pertinentes } \\
\text { el desarrollo de }\end{array}$ & & \\
\hline \multicolumn{2}{|c|}{$\begin{array}{l}\text { 7. Se relacionan y describen las estrategias didácticas de } \\
\text { enseñanza }\end{array}$} & & \\
\hline \multicolumn{2}{|c|}{$\begin{array}{l}\text { 8. Se relaciona de manera explícita el tipo de actividades } \\
\text { evaluativas a desarrollar para la verificación del éxito del } \\
\text { proceso de enseñanza y aprendizaje. }\end{array}$} & & \\
\hline \multicolumn{2}{|c|}{$\begin{array}{l}\text { 9. Las actividades evaluativas se diseñan en torno a las } \\
\text { competencias básicas y el desarrollo de habilidades } \\
\text { cognitivas. }\end{array}$} & & \\
\hline
\end{tabular}

Fuente: elaboración propia.

de actividades como la lectura de textos con preguntas hacia los alumnos (1.3) y actividades de copia o realización de dibujos (1.5) y proyección de videos o actividades de indagación (1.8) representaron actividades menos frecuentes (presentadas en 2 clases). Las actividades tradicionales como los dictados (1.4) y las pertinentes como los experimentos para el área de Ciencias Naturales (1.6) no fueron tenidas en cuenta, según las evidencias obtenidas.

En lo concerniente al paso 2, relacionado con la identificación de los episodios de las actividades educativas del aula, según su objetivo, las prácticas pedagógicas se caracterizaron por la nula gestión instruccional del maestro hacia los estudiantes (aspecto 1.1). Es decir, que en ninguna de las clases observadas los maestros presentaron los objetivos relacionados con la clase o las tareas asignadas; los conceptos (2.1) o aspectos declarativos, conceptuales o teóricos constituyeron el principal contenido priorizado tanto para las actividades de indagación como de transmisión y evaluación. Los resultados de este paso se presentan a en la tabla 6 . 
Tabla 5. Características pedagógicas y didácticas de las prácticas de aula del área de Química (actividades educativas planteadas por el maestro).

\begin{tabular}{|c|c|c|c|}
\hline Paso & \multicolumn{3}{|c|}{ Actividad } \\
\hline \multirow{23}{*}{ 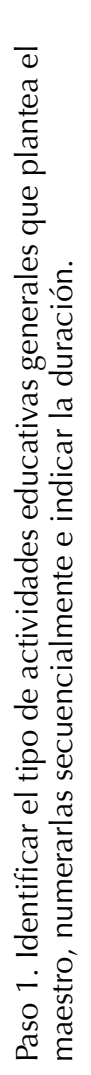 } & \multirow{9}{*}{ 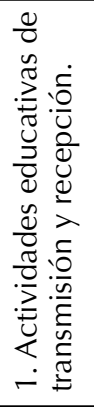 } & Aspecto & $\%$ de evidencia \\
\hline & & 1.1. Exposición del maestro. & $100 \%$ \\
\hline & & 1.2. Exposición del maestro con preguntas a los alumnos. & $100 \%$ \\
\hline & & 1.7. Contestar preguntas por escrito o de forma oral. & $100 \%$ \\
\hline & & 1.3. Lectura de textos con preguntas a los alumnos. & $25 \%$ \\
\hline & & 1.5. Copiar textos o dibujos. & $25 \%$ \\
\hline & & 1.8. Proyección de videos y actividades de indagación. & $25 \%$ \\
\hline & & 1.4. Dictados. & $0 \%$ \\
\hline & & 1.6. Presentación de experimentos. & $0 \%$ \\
\hline & \multirow{14}{*}{ 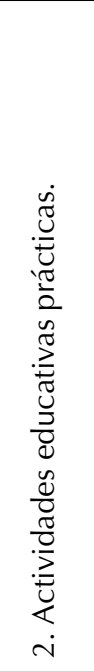 } & 2.11. Realización de proyectos. & $13 \%$ \\
\hline & & 2.1. Elaborar preguntas. & $0 \%$ \\
\hline & & $\begin{array}{l}\text { 2.2. Contestar preguntas que requieren procesos cognitivos complejos y } \\
\text { desafiantes para los alumnos. }\end{array}$ & $0 \%$ \\
\hline & & 2.3. Realizar una redacción, un artículo. & $0 \%$ \\
\hline & & 2.4. Elaborar presentaciones gráficas. & $0 \%$ \\
\hline & & 2.5. Análisis de dibujos y gráficas. & $0 \%$ \\
\hline & & 2.6. Análisis de representaciones gráficas. & $0 \%$ \\
\hline & & 2.7. Elaboración de dibujos y gráficas. & $0 \%$ \\
\hline & & 2.8. Elaboración de representaciones gráficas. & $0 \%$ \\
\hline & & 2.9. Búsqueda de información. & $0 \%$ \\
\hline & & 2.10. Realización de experimentos. & $0 \%$ \\
\hline & & 2.12. Exposición de trabajos. & $0 \%$ \\
\hline & & 2.13. Discusión/debates. & $0 \%$ \\
\hline & & 2.14. Realizar juegos mentales. & $0 \%$ \\
\hline
\end{tabular}

Fuente: elaboración propia adaptada de Fernández et al. (2010)

Tabla 6. Resultados del análisis y registro de las características pedagógicas y didácticas de las prácticas de aula del área de Química (episodios de las actividades educativas según su objetivo).

\begin{tabular}{|c|c|c|c|}
\hline Paso & \multicolumn{3}{|c|}{ Actividad } \\
\hline \multirow{11}{*}{ 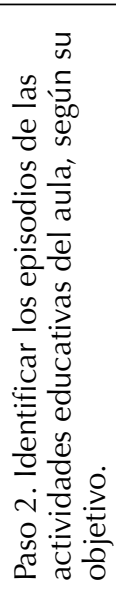 } & \multicolumn{2}{|r|}{ Aspecto } & $\%$ de evidencia \\
\hline & $\begin{array}{l}\text { 1. Gestión. Dar instrucciones sobre } \\
\text { cómo ejecutar una tarea, designación } \\
\text { de actividades a los alumnos. }\end{array}$ & 1.1. Instrucciones de ejecución. & $0 \%$ \\
\hline & \multirow{3}{*}{$\begin{array}{l}\text { 2. Indagar el conocimiento previo } \\
\text { del alumno sobre: }\end{array}$} & 2.1. Conceptos. & $100 \%$ \\
\hline & & 2.2. Procedimientos. & $0 \%$ \\
\hline & & 2.3. Actitudes. & $0 \%$ \\
\hline & \multirow{3}{*}{ 3. Transmitir conocimientos sobre: } & 3.1. Conceptos. & $100 \%$ \\
\hline & & 3.2. Procedimientos & $25 \%$ \\
\hline & & 3.3. Actitudes. & $0 \%$ \\
\hline & \multirow{3}{*}{$\begin{array}{l}\text { 4. Evaluar la comprensión de los } \\
\text { alumnos sobre: }\end{array}$} & 4.1. Conceptos. & $100 \%$ \\
\hline & & 4.2. Procedimientos & $0 \%$ \\
\hline & & 4.3. Actitudes. & $0 \%$ \\
\hline
\end{tabular}

Fuente: elaboración propia adaptada de Fernández et al. (2010) 
En lo concerniente al paso 3 del instrumento, el cual presenta las acciones que realiza el profesor para lograr el objetivo del episodio, los resultados obtenidos se presentan en la tabla 7 .

En este paso se evidenció en el $88 \%$ de los casos los docentes presentan instrucciones sobre las tareas a realizar (aspecto 1.1), y estas actividades se basaron en su totalidad en la descripción de conceptos principalmente (aspecto 2.1), dejando a un lado aspectos fundamentales de las prácticas de aula como la clasificación, comparación o explicación de los fenómenos naturales o modelos conceptuales elaborados por los estudiantes. Las preguntas realizadas durante las clases fueron mayoritariamente cerradas y objetivas (3.1). Es decir, preguntas orientadas específicamente a los conceptos o definiciones teóricas de los contenidos conceptuales abordados.

De forma paralela, se registró una menor frecuencia durante la clase la propuesta de planteamientos de preguntas subjetivas (3.2) que permitieran establecer la opinión o punto de vista particular del estudiante y de preguntas abiertas, con igual relevancia (25\%) durante su presentación (aspectos 4.1 y 4.2).
En cuanto a las estrategias en la evaluación y la participación de los alumnos (pasos 5 y 6, respectivamente) las prácticas de aula analizadas observadas priorizaron la corrección de errores en los alumnos y la manifestación de la respuesta correcta, tal como se presenta en la tabla 8.

El mayor porcentaje de evidencia lo presenta el aspecto de corrección de errores de los alumnos por parte del docente (aspecto 6.1), seguida de la valoración positiva del trabajo de los alumnos; es decir, sus aciertos (4.1) y la valoración negativa (5.1) durante sus equivocaciones. Con el fin de estimular la participación del alumnado todos los docentes enfatizaron en la promoción de un clima de confianza y respeto en el aula (2.1), el $50 \%$ de ellos en el desarrollo de actividades para controlar la disciplina (3.1) y en menor medida actividades para propiciar la participación de estudiantil (1.1).

De acuerdo con el paso 6, relacionado con la organización de los alumnos en cada actividad educativa y episodio, los resultados obtenidos son se pueden ver en la tabla 9.

Tabla 7. Resultados del análisis y registro de las características pedagógicas y didácticas de las prácticas de aula del área de Química (acciones realizadas por el profesor para lograr el objetivo del episodio).

\begin{tabular}{|c|c|c|c|}
\hline \multirow{2}{*}{ Paso } & \multicolumn{3}{|c|}{ Actividad } \\
\hline & \multicolumn{2}{|r|}{ Aspecto } & $\%$ de evidencia \\
\hline \multirow{10}{*}{ 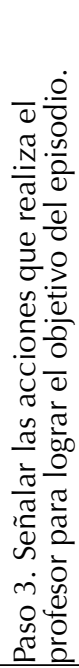 } & $\begin{array}{l}\text { 1. Presentación de instrucciones sobre } \\
\text { la tarea. }\end{array}$ & 1.1 Actividades de orientación sobre las tareas a realizar. & $88 \%$ \\
\hline & \multirow{5}{*}{ 2. Presentación de conocimientos. } & 2.1. Descripción de conceptos/procedimientos/actitudes. & $100 \%$ \\
\hline & & $\begin{array}{l}\text { 2.2. Clasificación de las características de conceptos/ } \\
\text { procedimientos/actitudes. }\end{array}$ & $0 \%$ \\
\hline & & \begin{tabular}{|llll}
$\begin{array}{l}\text { 2.3. Comparación o relación de } \\
\text { procedimientos/actitudes distintas. }\end{array}$ & & conceptos/ \\
\end{tabular} & $0 \%$ \\
\hline & & $\begin{array}{l}\text { 2.4. Explicación de un fenómeno o proceso a partir de un } \\
\text { modelo conceptual }\end{array}$ & $0 \%$ \\
\hline & & $\begin{array}{l}\text { 2.5. Explicación o planificación procedimental. Analiza } \\
\text { las estrategias, operaciones o decisiones relativas a un } \\
\text { procedimiento o método }\end{array}$ & $0 \%$ \\
\hline & \multirow{2}{*}{ 3. Realización de preguntas cerradas. } & 3.1. Objetivas. & $63 \%$ \\
\hline & & 3.2. Subjetivas. & $25 \%$ \\
\hline & \multirow{2}{*}{ 4. Realización de preguntas abiertas. } & 4.1. Objetivas. & $25 \%$ \\
\hline & & 4.2. Subjetivas. & $25 \%$ \\
\hline
\end{tabular}

Fuente: elaboración propia adaptada de Fernández et al. (2010) 
Tabla 8. Resultados del análisis y registro de las características pedagógicas y didácticas de las prácticas de aula del área de Química (estrategias de evaluación y participación estudiantil).

\begin{tabular}{|c|c|c|c|}
\hline \multirow{2}{*}{ Paso } & \multicolumn{3}{|c|}{ Actividad } \\
\hline & \multicolumn{2}{|r|}{ Aspecto } & $\%$ de evidencia \\
\hline \multirow{6}{*}{ 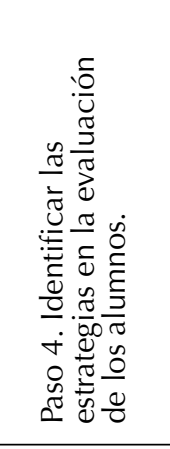 } & $\begin{array}{l}\text { 6. Corregir los errores de los } \\
\text { alumnos. }\end{array}$ & $\begin{array}{l}\text { 6.1 Tipo de corrección de errores de los alumnos y } \\
\text { manifestación de la respuesta correcta. }\end{array}$ & $100 \%$ \\
\hline & $\begin{array}{l}\text { 4. Valorar positivamente el trabajo de } \\
\text { los alumnos. }\end{array}$ & $\begin{array}{l}\text { 4.1 Tipo de valoración positiva del trabajo de los } \\
\text { alumnos. }\end{array}$ & $88 \%$ \\
\hline & $\begin{array}{l}\text { 5. Valorar negativamente el trabajo } \\
\text { de los alumnos. }\end{array}$ & $\begin{array}{l}\text { 5.1 Tipo de valoración negativa del trabajo de los } \\
\text { alumnos. }\end{array}$ & $88 \%$ \\
\hline & 1. Indagar sobre los errores. & 1.1 Tipo de actividad indagativa de errores. & $0 \%$ \\
\hline & $\begin{array}{l}\text { 2. Crear situaciones de conflicto } \\
\text { cognitivo. }\end{array}$ & 2.1 Tipo de situaciones de conflicto cognitivo. & $0 \%$ \\
\hline & $\begin{array}{l}\text { 3. Proporcionar estrategias } \\
\text { metacognitivas. }\end{array}$ & 3.1 Tipo de estrategias metacognitivas proporcionadas. & $0 \%$ \\
\hline \multirow{3}{*}{ 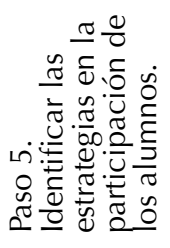 } & $\begin{array}{l}\text { 2. Promover un clima de confianza y } \\
\text { respeto en el aula. }\end{array}$ & $\begin{array}{l}\text { 2.1 Tipo de actividad de promoción de un clima de } \\
\text { confianza y respeto en el aula. }\end{array}$ & $100 \%$ \\
\hline & 3. Control de la disciplina. & 3.1 Tipo de actividad para controlar la disciplina. & $50 \%$ \\
\hline & $\begin{array}{l}\text { 1. Promover la participación de los } \\
\text { alumnos. }\end{array}$ & $\begin{array}{l}\text { 1.1 Tipo de actividad de promoción de la participación } \\
\text { de los alumnos. }\end{array}$ & $38 \%$ \\
\hline
\end{tabular}

Fuente: elaboración propia adaptada de Fernández et al. (2010)

Tabla 9. Resultados del análisis y registro de las características pedagógicas y didácticas de las prácticas de aula del área de Química (organización de los alumnos en cada episodio).

\begin{tabular}{|c|c|c|c|}
\hline \multirow[b]{2}{*}{ Paso } & \multicolumn{3}{|c|}{ Actividad } \\
\hline & \multicolumn{2}{|r|}{ Aspecto } & $\begin{array}{c}\% \text { de } \\
\text { evidencia }\end{array}$ \\
\hline \multirow{8}{*}{ 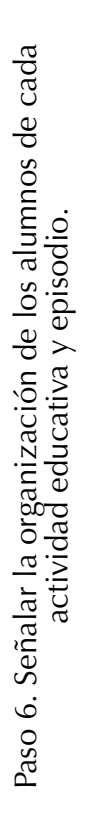 } & 1. Grupo clase. & 1.1 Actividades de carácter general: grupo clase. & $100 \%$ \\
\hline & 2. Trabajo individual. & 2.1 Actividades de trabajo individual. & $25 \%$ \\
\hline & 3. Trabajo en grupos. & 3. Actividades de trabajo en grupos. & $0 \%$ \\
\hline & $\begin{array}{l}\text { 4. Trabajo cooperativo } \\
\text { en grupos. }\end{array}$ & 4. Actividades de trabajo cooperativo en grupos. & $0 \%$ \\
\hline & \multirow{2}{*}{$\begin{array}{l}\text { A. Estructuras iniciadas } \\
\text { por el profesor: }\end{array}$} & $\begin{array}{l}\text { A.2. IRE. La secuencia es iniciada por el profesor (I), a través de una } \\
\text { pregunta (generalmente cerrada). El alumno responde o realiza la tarea } \\
\text { (R) y se produce un comentario evaluativo (E). La retroalimentación del } \\
\text { profesor es simple: sí/no, bien/mal o puede que el maestro no diga nada } \\
\text { indicando confirmación. }\end{array}$ & $100 \%$ \\
\hline & & $\begin{array}{l}\text { A.3. IRF. Como IRE, pero el profesor hace preguntas abiertas que } \\
\text { requieren una mayor elaboración por parte de los alumnos y hay un } \\
\text { seguimiento o retroalimentación del profesor, quien reformula, completa } \\
\text { y no simplemente evalúa como en IRE. }\end{array}$ & $0 \%$ \\
\hline & \multirow[b]{2}{*}{$\begin{array}{l}\text { B. Estructuras iniciadas } \\
\text { espontáneamente por el } \\
\text { alumno. }\end{array}$} & $\begin{array}{l}\text { B.1. A-P. La secuencia es iniciada espontáneamente por el alumno } \\
\text { que plantea una pregunta, generalmente cerrada, al profesor, y este le } \\
\text { contesta. }\end{array}$ & $0 \%$ \\
\hline & & $\begin{array}{l}\text { B.2. Estructuras simétricas. La secuencia comunicativa es iniciada } \\
\text { espontáneamente por los alumnos que aportan información sobre el } \\
\text { tema, por ejemplo, en los debates. B.2.1. A-A. Un alumno se dirige a otro } \\
\text { alumno B.2.2. A-P. Un alumno se dirige al maestro. B.2.3. A-Grupo. Un } \\
\text { alumno se dirige al grupo clase. }\end{array}$ & $0 \%$ \\
\hline
\end{tabular}

Fuente: elaboración propia adaptada de Fernández et al. (2010) 
Teniendo en cuenta estos resultados, se puede evidenciar que en la totalidad de las prácticas de aula se presentó una organización general, (grupo clase (1.1), y solo en una de ellas se promovió en un pequeño segmento el trabajo individual de los estudiantes (1.2); mientras que el desarrollo de actividades grupales como el trabajo en grupo y cooperativo fue nulo durante las clases observadas.

Por otra parte, todas las secuencias didácticas fueron iniciadas por los profesores, tal como lo muestra la tabla 11, en las cuales los alumnos solamente se limitaban a responder las tareas a través de una retroalimentación simple por parte del profesor (A.2), carente de preguntas abiertas que promuevan una mayor exigencia cognitiva de los alumnos.

Seguidamente, la estructura comunicativa (paso 7) se caracterizó por el dominio de los docentes, quienes se dirigieron de manera mayoritaria (A.1), siendo ellos quienes iniciaban las secuencias a través de preguntas cerradas relacionadas con el contenido de la clase (A.2). En ninguna de las clases observadas, tal como se presenta en la tabla 10, las secuencias fueron iniciadas de manera espontánea por los alumnos ni se promovió el intercambio comunicativo entre ellos.

Teniendo en cuenta el carácter tradicional y conductista de las prácticas de aula según las descripciones anteriores, las acciones del alumno de cada episodio descritas en la tabla 11 y concernientes al paso 8 del instrumento se caracterizaron por la escucha pasiva de las instrucciones sobre la tarea a realizar (A.1).

Se puede evidenciar la influencia de actividades de respuestas a preguntas relacionadas principalmente con conceptos teóricos (A.6), así como el contestar preguntas cerradas o abiertas que reproducían textualmente los conocimientos escolares; mientras que en menor medida se presentó la copia de información de conceptos, procedimientos y actitudes (A.3), la exposición de información (A.5) y la lectura de textos (A.4). Igualmente, se evidenció una escasa promoción a la experimentación mediante artefactos y el trabajo manipulativo en el laboratorio (aspecto B.1 con un $13 \%$ ).

Tabla 10. Resultados del análisis y registro de las características pedagógicas y didácticas de las prácticas de aula del área de Química (características de la estructura comunicativa).

\begin{tabular}{|c|c|c|c|}
\hline \multirow{2}{*}{ Paso } & \multicolumn{3}{|c|}{ Actividad } \\
\hline & \multicolumn{2}{|r|}{ Aspecto } & $\%$ de evidencia \\
\hline \multirow{5}{*}{ 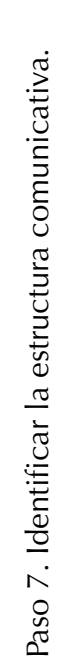 } & \multirow{3}{*}{$\begin{array}{l}\text { A. Estructuras } \\
\text { iniciadas por el } \\
\text { profesor: }\end{array}$} & $\begin{array}{l}\text { A.1. P-A. El profesor se dirige a los alumnos (por ejemplo, en la presentación } \\
\text { de conocimientos). }\end{array}$ & $100 \%$ \\
\hline & & $\begin{array}{l}\text { A.2. IRE. La secuencia es iniciada por el profesor (I), a través de una pregunta } \\
\text { (generalmente cerrada) o con una indicación sobre la tarea de aprendizaje. } \\
\text { El alumno responde o realiza la tarea (R) y se produce un comentario } \\
\text { evaluativo (E). La retroalimentación del profesor es simple: sí/no, bien/mal o } \\
\text { puede que el maestro no diga nada indicando confirmación. }\end{array}$ & $100 \%$ \\
\hline & & $\begin{array}{l}\text { A.3. IRF. Como IRE, pero el profesor hace preguntas abiertas que requieren } \\
\text { una mayor elaboración por parte de los alumnos y hay un seguimiento o } \\
\text { retroalimentación del profesor, quien reformula, completa y no simplemente } \\
\text { evalúa como en IRE. }\end{array}$ & $0 \%$ \\
\hline & \multirow[b]{2}{*}{$\begin{array}{l}\text { B. Estructuras } \\
\text { iniciadas } \\
\text { espontáneamente } \\
\text { por el alumno. }\end{array}$} & $\begin{array}{l}\text { B.1. A-P. La secuencia es iniciada espontáneamente por el alumno que } \\
\text { plantea una pregunta, generalmente cerrada, al profesor, y este le contesta. }\end{array}$ & $0 \%$ \\
\hline & & $\begin{array}{l}\text { B.2. Estructuras simétricas. La secuencia comunicativa es iniciada } \\
\text { espontáneamente por los alumnos que aportan información sobre el tema, } \\
\text { por ejemplo, en los debates. B.2.1. A-A. Un alumno se dirige a otro alumno } \\
\text { B.2.2. A-P. Un alumno se dirige al maestro. B.2.3. A-Grupo. Un alumno se } \\
\text { dirige al grupo clase. }\end{array}$ & $0 \%$ \\
\hline
\end{tabular}

Fuente: elaboración propia adaptada de Fernández et al. (2010) 
Tabla 11. Resultados del análisis y registro de las características pedagógicas y didácticas de las prácticas de aula del área de Química (acciones del alumno en cada episodio).

\begin{tabular}{|c|c|c|c|}
\hline \multirow[b]{2}{*}{ Paso } & \multicolumn{3}{|c|}{ Actividad } \\
\hline & \multicolumn{2}{|r|}{ Aspecto } & $\begin{array}{c}\text { \% de } \\
\text { evidencia }\end{array}$ \\
\hline \multirow{22}{*}{ 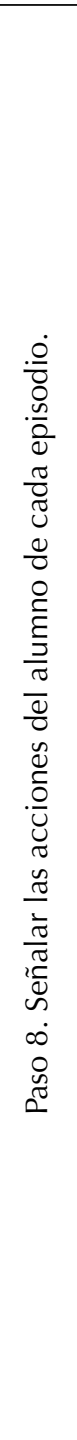 } & \multirow{6}{*}{$\begin{array}{l}\text { A. Acciones de recepción y } \\
\text { repetición de conocimientos } \\
\text { derivadas de las indicaciones } \\
\text { del maestro. }\end{array}$} & A.1. Escucha instrucciones sobre la tarea. & $100 \%$ \\
\hline & & A.2. Escucha información sobre conceptos/procedimientos/actitudes. & $100 \%$ \\
\hline & & $\begin{array}{l}\text { A.6. Contesta preguntas cerradas o abiertas que reproducen textualmente } \\
\text { los conocimientos escolares. }\end{array}$ & $100 \%$ \\
\hline & & A.3. Copia información sobre conceptos/procedimientos/actitudes. & $88 \%$ \\
\hline & & $\begin{array}{l}\text { A.5. Expone información sobre conceptos/procedimientos/actitudes } \\
\text { extraídos textualmente de fuentes como el libro de texto, Internet, etc. }\end{array}$ & $50 \%$ \\
\hline & & A.4. Lee textos escolares en voz alta o de manera silenciosa. & $38 \%$ \\
\hline & $\begin{array}{l}\text { B. Acciones manipulativas } \\
\text { por indicaciones del maestro }\end{array}$ & B.1. Realiza experimentos, artefactos, trabajo manipulativo en el laboratorio. & $13 \%$ \\
\hline & \multirow{8}{*}{$\begin{array}{l}\text { C. Acciones que implican } \\
\text { una reestructuración de } \\
\text { conocimientos derivadas de } \\
\text { las indicaciones del maestro. }\end{array}$} & $\begin{array}{l}\text { C.1. Define o representa un concepto/procedimiento/actitud integrando } \\
\text { información de distintas fuentes o con sus propias palabras. }\end{array}$ & $50 \%$ \\
\hline & & $\begin{array}{l}\text { C.7. Expresar sus opiniones o lo que sabe sobre un tema a partir de la } \\
\text { experiencia cotidiana. }\end{array}$ & $88 \%$ \\
\hline & & C.3. Observa y registra información. & $13 \%$ \\
\hline & & C.2. Relaciona, compara distintos conceptos/procedimientos/actitudes. & $0 \%$ \\
\hline & & $\begin{array}{l}\text { C.4. Selecciona información pertinente de datos, identifica variables, } \\
\text { problemas. }\end{array}$ & $0 \%$ \\
\hline & & C.5. Elabora conjeturas o hipótesis, realiza predicciones. & $0 \%$ \\
\hline & & $\begin{array}{l}\text { C.6. Elabora explicaciones, interpretar datos a partir de modelos, hechos, } \\
\text { principios. }\end{array}$ & $0 \%$ \\
\hline & & $\begin{array}{l}\text { C.8. Evaluar, criticar, opinar sobre su propio trabajo y/o las ideas y el trabajo } \\
\text { de sus compañeros y el de otras personas. }\end{array}$ & $0 \%$ \\
\hline & \multirow{3}{*}{$\begin{array}{l}\text { D. Acciones que implican } \\
\text { una reestructuración de } \\
\text { conocimientos originadas por } \\
\text { iniciativa del alumno. }\end{array}$} & D.1. Realiza preguntas al profesor que tienen que ver con el tema. & $88 \%$ \\
\hline & & D.2. Expresa por propia iniciativa sus opiniones o lo que sabe sobre el tema. & $13 \%$ \\
\hline & & $\begin{array}{l}\text { D.3. Evaluar, criticar, opinar sobre su propio trabajo y/o las ideas y el trabajo } \\
\text { de sus compañeros y el de otras personas. }\end{array}$ & $0 \%$ \\
\hline & \multirow{4}{*}{$\begin{array}{l}\text { E. Otras acciones originadas } \\
\text { por iniciativa del alumno }\end{array}$} & $\begin{array}{l}\text { E.3. Quejas, críticas, comentarios sobre cuestiones de disciplina de otros } \\
\text { alumnos. }\end{array}$ & $75 \%$ \\
\hline & & E.1. Formula preguntas de gestión, pide pautas de trabajo al profesor. & $0 \%$ \\
\hline & & E.2. Solicita pautas de evaluación. & $0 \%$ \\
\hline & & E.4. Quejas o críticas a las demandas del maestro. & $0 \%$ \\
\hline
\end{tabular}

Fuente: elaboración propia adaptada de Fernández et al. (2010)

Además, se pudo comprobar la escasa participación autónoma de los estudiantes, principalmente en las actividades que promovieran la definición o representación de un concepto/procedimiento/ actitud integrando información de distintas fuentes o con sus propias palabras (C.1), la expresión de opiniones o lo que sabe sobre un tema a partir de la experiencia cotidiana (C.7), así como en la observación y el registro de información (C.3), la realización de preguntas al profesor que tenían que ver con el tema (D.1), las expresiones por propia iniciativa de sus opiniones o lo que sabían sobre el tema (D.2) y, mayoritariamente, las manifestaciones de los estudiantes se relacionaban con quejas, 
críticas, comentarios sobre cuestiones de disciplina de otros alumnos (E.3).

En lo respectivo al grado de participación de los alumnos en los episodios de las clases, previsto en el paso 9 del instrumento, se pudo observar que son los profesores quienes orientan estrechamente la participación de los alumnos. Esto mediante la exposición de la información o realizando directamente las actividades educativas, lo que minimizó o anuló el margen de libertad o participación estudiantil o, en su defecto, permitiendo la responsabilidad total de estos en el desarrollo de los procesos de enseñanza y aprendizaje. La síntesis de este paso se aclara en la tabla 12.

\section{Conclusiones}

Tal como lo manifiesta el MEN (1998), la experiencia de la renovación curricular en nuestro país evidencia un avance hacia la calidad en las prácticas pedagógicas, y de las prácticas educativas en general, aspecto que no se garantiza con solamente contar con unos programas curriculares bien diseñados. Esto es insuficiente si la práctica pedagógica de los colectivos de docentes no está atravesada por el estudio permanente sobre los enfoques, procesos y competencias fundamentales que determinan el desarrollo integral de los estudiantes.

De acuerdo con esta premisa, difícilmente se avanzará hacia procesos de calidad; es decir, sin un ejercicio didáctico fundamentado teórica y reflexivamente mediante la continua construcción, evolución y progresión académica, producto de la investigación educativa aunada por disciplinas, cuerpos teóricos y perspectivas externas como la psicología y todas sus manifestaciones (psicolingüística, psicología educativa, psicología del aprendizaje, entre otras); además de su perspectiva histórica, la evolución de sus paradigmas, el peso de la tradición, sus crisis y las concepciones alternativas.

En este sentido, las principales conclusiones producto de los hallazgos producto del trabajo didáctico descriptivo, comprensivo y explicativo de la práctica pedagógica del área de Química, esbozados en el presente trabajo, no difieren de otros estudios investigativos.

Un currículo genérico basado en la concepción tradicional de la enseñanza y el aprendizaje, fundado en contenidos declarativos con propiedades ambiguas que no especifican el tipo de experiencias educativas privilegiadas en el aula; el cual mantiene la regulación gobiernista y sumisa entre

Tabla 12. Resultados del análisis y registro de las características pedagógicas y didácticas de las prácticas de aula del área de Química (grado de participación del alumno).

\begin{tabular}{|c|c|c|c|}
\hline \multirow[b]{2}{*}{ Paso } & \multicolumn{3}{|c|}{ Actividad } \\
\hline & \multicolumn{2}{|r|}{ Aspecto } & $\begin{array}{c}\% \text { de } \\
\text { evidencia }\end{array}$ \\
\hline \multirow{3}{*}{ 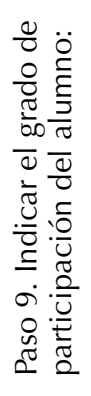 } & 1. Baja. & $\begin{array}{l}\text { 1.1 El profesor orienta estrechamente la participación del alumno en clase; expone } \\
\text { información o realiza directamente las actividades educativas, da indicaciones explícitas } \\
\text { a los alumnos, les realiza preguntas cerradas, frases inacabadas o preguntas abiertas en } \\
\text { las que el alumno tiene que repetir textualmente los conocimientos escolares. }\end{array}$ & $100 \%$ \\
\hline & 2. Media. & $\begin{array}{l}\text { 1.2 El profesor orienta la aportación del alumno con un mayor margen de libertad, } \\
\text { demanda o guía la participación del alumno mediante indicaciones o preguntas abiertas } \\
\text { que demandan al alumno una reelaboración de los conocimientos escolares. }\end{array}$ & $0 \%$ \\
\hline & 3. Alta. & $\begin{array}{l}\text { El alumno es el principal responsable de la acción y de la información que se hace } \\
\text { pública en el aula, realizando autónomamente las actividades, aportando por propia } \\
\text { iniciativa información nueva al contenido que se elabora o solicitando ayuda. }\end{array}$ & $0 \%$ \\
\hline
\end{tabular}

Fuente: elaboración propia adaptada de Fernández et al. (2010) 
los sujetos directos del proceso educativo: relación maestro-alumno, documentalmente en los curriculares institucionales (PEI, plan de estudio y plan de clase) no se explicita de manera clara y expedita la definición de un modelo pedagógico característico; además de los concernientes métodos y técnicas de enseñanza privilegiados institucionalmente. Aspectos que, por lo tanto, no permiten la justificación de manera pertinente sobre la necesidad formación en el ámbito científico de los estudiantes.

Esta falta de identidad pedagógica se configura mediante un conglomerado de directrices globales que no permiten la identificación y relación clara de las propuestas curriculares y pedagógicas características: las competencias científicas a promover a través de la formación en ciencias y el engranaje propuesto de los referentes pedagógicos (lineamientos curriculares y estándares básicos de competencia) establecidos por el MEN para la enseñanza de esta área.

En cuanto al componente de desarrollo pedagógico y didáctico de las prácticas de aula de la planificación, estas se basaron en la priorización de la exposición magistral del docente en torno a los contenidos declarativos en función de las temáticas conceptuales; con una marcada ausencia de actividades estimulantes de procesos cognitivos complejos y desafiantes para los alumnos en torno a los demás contenidos de enseñanza (procedimientos y actitudes).

A partir de los resultados obtenidos se puede concluir que las prácticas de enseñanza en el área de ciencias naturales, y específicamente del área de química, en los niveles de educación básica secundaria y media de la institución educativa objetivo de la investigación se caracteriza por la naturaleza magistral y conductista de la praxis, liderada por el actuar docente, aspectos que impiden que las secuencias sean iniciadas espontáneamente por los alumnos para que puedan elaborar conjeturas o hipótesis, predicciones, explicaciones, interpretación de datos a partir de modelos, hechos, principios; tal como lo establecen las directrices de la educación por competencias científicas en Colombia, limitando la promoción y consolidación de este tipo de habilidades relacionadas con la enseñanza de las ciencias.

Este tipo de iniciativas de investigación, desarrolladas por docentes del establecimiento educativo, permiten promover acciones e indagación y reflexión sobre las prácticas didácticas, en este caso, desde el área de ciencias naturales, que permitan incentivar la innovación, transformación y el fortalecimiento de las prácticas de aula desde el quehacer docente y con el involucramiento activo de los niños, niñas y jóvenes desde perspectivas constructivistas de la educación.

\section{Referencias}

Calderero, J. (2002). Estudio de libros de texto de ciencias de la naturaleza mediante análisis cuantitativo basado en la teoría de grafos. Tesis Doctoral, Universidad Complutense de Madrid, Facultad de Educación, Departamento de Didáctica de las Ciencias Experimentales. Madrid, España.

Calvo, A.; Martín, M. (2005). Análisis de la adaptación de los libros de texto de eso al currículo oficial, en el campo de la química. Departamento de Didáctica de las Ciencias Experimentales. Facultad de Educación de la Universidad Complutense de Madrid. Centro de Formación del Profesorado. España.

Castillo, A. (2011). Estrategias de enseñanza y sus condiciones para generar un aprendizaje significativo química. (Tesis de Maestría). Facultad de Humanidades y Educación. Programa de Enseñanza de la Química. Universidad del Zulia. Maracaibo, Venezuela.

Dulzaides, M.; Molina, A. (2004). Análisis documental y de información: dos componentes de un mismo proceso. ACIMED, Revista del Centro Nacional de Información de Ciencias Médicas de Cuba, 12(2).

Fernández, M.; Tuset, A.; Ross, G.; Leyva, A.; Alvídrez, A. (2010). Prácticas educativas constructivistas en clases de ciencias. Propuesta de 
un instrumento de análisis. REICE, Revista Iberoamericana sobre Calidad, Eficacia y Cambio en Educación, 8(1), 26-44.

Florez, R. (2005). Evaluación Pedagógica y cognición. Bogotá, Colombia: Editorial: McGraw-Hill.

Hernández, R., Fernández, C., y Baptista, P. (2010). Metodología de la Investigación. México D.F., México: Editorial McGra-Hill/Interamericana Editores S.A.

Instituto Colombiano para la Evaluación de la Educación (ICFES) (2015). Orientaciones para el examen de Estado de la educación media ICFES. SABER $11^{\circ}$. Bogotá.

Jiménez, J.; Perales, F. (2001). Aplicación del análisis secuencial al estudio del texto escrito e ilustraciones de los libros de física y química de la ESO. IES Cerro de los Infantes. Pinos Puente Granada, Departamento de Didáctica de las Ciencias Experimentales. Universidad de Granada.

Ministerio de Educación Nacional (MEN) (2013). Documento guía para la evaluación de competencias docente de media-Ciencias Naturales y Educación Ambiental (Química). Bogotá: Dirección de Calidad para la educación preescolar, básica y media, Subdirección de referentes y evaluación de la calidad educativa.

Ministerio de Educación Nacional (MEN) (2004). Guía de trabajo para los docentes, Taller de socialización de los normas básicas de competencia. Bogotá: Subdirección de normas y evaluación.

Ministerio de Educación Nacional (MEN) (2008). Fundamentación desde los referentes nacionales, lineamientos curriculares y normas básicos de competencias. Bogotá: MEN.
Ministerio de Educación Nacional (MEN) (2007). Plan de Clases. Orientaciones curriculares para el diseño de los planes de clases. Subdirección de Estándares y Evaluación del Ministerio de Educación. Portal Colombia Aprende. http:// www.colombiaaprende.edu.co/html/docentes/1596/article-121199.html

Ministerio de Educación Nacional (MEN) (2006). Estándares Básicos de Competencias en Lenguaje, Matemáticas, Ciencias y Ciudadanas. Guía sobre lo que los estudiantes deben saber y saber hacer con lo que aprende. Bogotá: MEN.

Ministerio de Educación Nacional (MEN) (1998). Lineamientos curriculares del área de ciencias naturales y educación ambiental. http://www. colombiaaprende.edu.co/html/competencias/1746/articles-335459_pdf_6.pdf

Organización para la Cooperación y el Desarrollo Económico (OCDE) (2012). Programa Internacional de Evaluación de Estudiantes PISA. Resultados de la aplicación de los instrumentos de evaluación, prueba 2012 Proyecto coordinado por la OCDE.

Organización de las Naciones Unidas para la Educación, la Ciencia y la Cultura (Unesco) (1998). Informe de la Comisión Internacional sobre la Educación para el Siglo XXI. Ediciones Unesco.

Pérez, M.; Rincón, G. (2009). Actividad, secuencia didáctica y pedagogía por proyectos: tres alternativas para la organización del trabajo didáctico en el campo del lenguaje.

Tobón, S.; Pimienta, J.; García, J. (2010). Secuencias didácticas: aprendizaje y evaluación de competencias. México D. F.: Pearson Educación. 


\section{Anexo 1 \\ Instrumento 1 \\ Lista de cotejo: Análisis del ámbito de diseño y planificación curricular institucional y del área de Química}

Dimensión: Diseño y planificación de las actividades pedagógico-didácticas

Subdimensión: Diseño y planificación institucional

El instrumento 1 hace parte del conjunto de herramientas de análisis y descripción de las características de la práctica pedagógica desarrollada en el área de química en la institución educativa a través objeto de estudio en su componente de planificación.

A través de un proceso inductivo-deductivo partiendo de las características generales del proyecto Educativo Institucional PEI de la institución educativa y las características específicas de cada uno de los planes de área de los niveles educativos ofrecidos por la institución. A través del instrumento 1 se pretende alcanzar tres objetivos principales: a) la descripción de las características Curriculares Generales del PEI como punto de partida para b) determinar aquellas características curriculares particulares relacionadas con el desarrollo de competencias científicas y finalmente poder c) establecer la relación entre sus aspectos estructurales y los fundamentos de la educación por Competencias del Sistema Educativo Colombiano que sirven de orientación y apoyo. Con el fin de medir y alcanzar los objetivos propuestos el instrumento diseñado consta de ítems:

Ítem 1. Denominado Información General que contempla la identificación del PEl y los referentes normativos de Colombia para su diseño en todas las instituciones educativas del país.

Ítem 2. Denominado Relación de los aspectos estructurales del PEI de la institución educativa y los fundamentos de la educación por Competencias del Sistema Educativo Colombiano. Permitirá establecer la relación de cada uno de los aspectos estructurales particulares del PEI de la institución educativa objeto de estudio y los fundamentos de la educación por Competencias establecidos en el Sistema Educativo Colombiano.

Ítem 3. Denominado Características Curriculares Generales y Particulares del PEI: Pedagógico-didácticas y de competencias científicas a través del cual se describirán las características curriculares generales y particulares del PEl: Pedagógico-didácticas relacionadas directamente con el desarrollo de competencias científicas a través del análisis de criterios pedagógicos fundamentales para todo proceso educativo: La Meta de formación, el proceso a través del cual se pretende alcanzar, los contenidos curriculares desarrollados, las características de la relación maestro alumno y los métodos y técnicas de enseñanza; aspectos basados en lo planteado por lo plantea Rafael Flórez Ochoa en su trabajo denominado Evaluación Pedagógica y cognición, Flórez (2005). En cada uno de los ítems planteados en el instrumento se establece la ubicación exacta de cada aspecto curricular analizada en la fuente de información relacionada (PEI de la institución Educativa Centro de Integración Popular IPC del municipio de Riohacha). 


\section{Información General}

Documento

Referentes normativos del sistema Educativo Colombiano aplicables al documento
Proyecto Educativo Institucional PEI de la Institución Educativa Centro de Integración Popular

\section{Relación de los aspectos estructurales del PEI de la institución educativa y los fundamentos de la educación por Competencias del Sistema Educativo Colombiano}

\begin{tabular}{|l|l|l|l|l|}
\hline \multirow{2}{*}{ Aspecto } & \multicolumn{2}{|c|}{$\begin{array}{c}\text { Se presenta en el } \\
\text { documento }\end{array}$} & \multirow{2}{*}{$\begin{array}{c}\text { Ubicación en el } \\
\text { documento }\end{array}$} & $\begin{array}{c}\text { Observaciones relacionadas con el } \\
\text { sistema educativo por competencias }\end{array}$ \\
\cline { 2 - 4 } & Si & No & & \\
\hline Filosofía Institucional & & & & \\
\hline $\begin{array}{l}\text { Análisis de la situación institucional: } \\
\text { Identificación de problemas y } \\
\text { orígenes }\end{array}$ & & & & \\
\hline $\begin{array}{l}\text { Objetivos Generales del Proyecto } \\
\text { Institucional }\end{array}$ & & & & \\
\hline $\begin{array}{l}\text { Estrategia Pedagógica de Guía para } \\
\text { las labores de formación de los } \\
\text { educandos }\end{array}$ & & & & \\
\hline $\begin{array}{l}\text { Planes de estudio. Definición } \\
\text { de criterios de evaluación del } \\
\text { rendimiento del educando }\end{array}$ & & & & \\
\hline Proyectos transversales & & & \\
\hline Sistema de matrículas y pensiones & & & & \\
\hline $\begin{array}{l}\text { Procedimientos de relación con } \\
\text { otras organizaciones sociales }\end{array}$ & & & & \\
\hline $\begin{array}{l}\text { Evaluación de recursos. Humanos, } \\
\text { físicos, económicos y tecnológicos }\end{array}$ & & & & \\
\hline $\begin{array}{l}\text { Estrategias de articulación } \\
\text { institucional con las expresiones } \\
\text { culturales locales y regionales }\end{array}$ & & & & \\
\hline Organigrama & & & \\
\hline
\end{tabular}




\section{Características Curriculares Generales y Particulares del PEI: Pedagógico-didácticas y de competencias científicas}

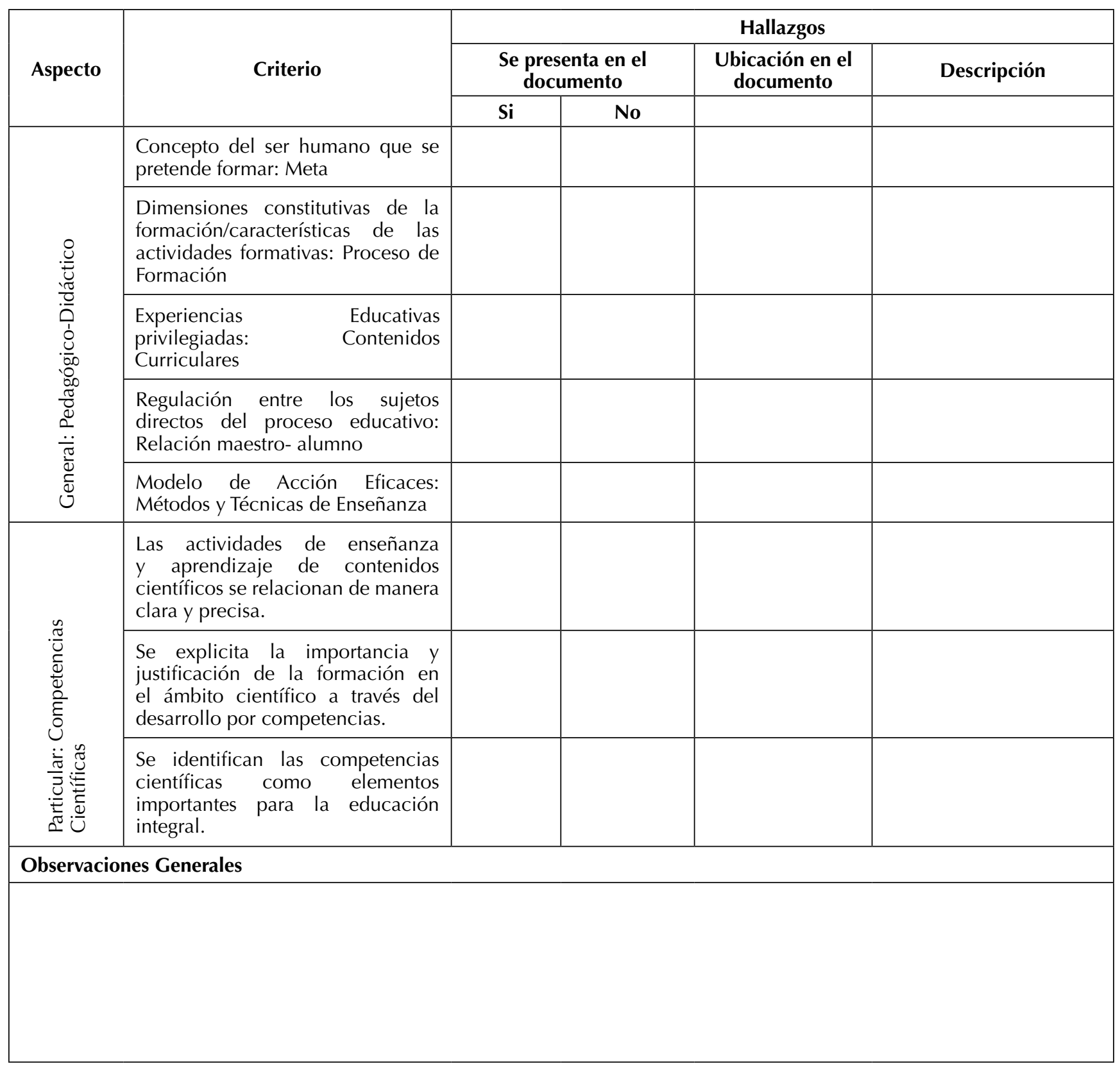




\section{Anexo 2. Guía de observación: Análisis descriptivo de la práctica pedagógica de la clase de Química}

Dimensión: Implementación y Desarrollo Pedagógico Didáctico

Subdimensión: Diseño y lineamientos pedagógico-didácticos para la formación en el área de química

A través del instrumento, se pretende analizar y describir la práctica pedagógica característica del are de química desarrollada en las aulas de clase. El instrumento fue diseñado con base en el trabajo de Fernández y col (2010) denominado prácticas educativas constructivistas en clases de ciencias. Propuesta de un instrumento de análisis REICE publicado en la Revista Iberoamericana sobre Calidad, Eficacia y Cambio en Educación, vol. 8, núm. 1 a través de la Red Iberoamericana de Investigación Sobre Cambio y Eficacia Escolar España. Documento que de acuerdo a sus características de análisis basadas en el paradigma constructivista es pertinente y se relaciona de forma pedagógica y didáctica con los objetivos del presente trabajo basado en la educación por competencias.

El instrumento se basa en el análisis de 4 interrogantes pedagógicos fundamentales: ¿Qué enseñan los docentes? ¿Cómo enseñan los docentes? ¿Qué hacen los estudiantes durante las clases? y ¿cómo interactúan los docentes y estudiantes durante las clases de química?

Para efectos de desarrollar de manera organizada y estructurada el análisis objetivo de la práctica pedagógica el instrumento plantea 9 pasos diferenciados basados en los distintos momentos o fases desarroIladas durante una clase de aula, los cuales, al ser relacionados con los interrogantes descritos pueden ser desarrollados de manera repetitiva de acuerdo a los objetivos del evaluador de la práctica.

El instrumento de aplicación, recolección y análisis de información derivada de la práctica pedagógica a evaluar se muestran en el documento titulado guía de observación: análisis descriptivo de la práctica pedagógica de la clase de química. 


\title{
Anexo 2. Guía de observación: análisis descriptivo de la práctica pedagógica de la clase de química (continuación)
}

\author{
Interrogantes y dimensiones establecidos como referentes de análisis de la práctica pedagógica en el \\ aula a través del instrumento
}

\begin{tabular}{|c|c|}
\hline \multicolumn{2}{|r|}{ Dimensión } \\
\hline Interrogante de Análisis & Conceptualización de la dimensión de Análisis \\
\hline $\begin{array}{l}\text { 1. ¿Qué enseñan los } \\
\text { docentes del área de } \\
\text { química? }\end{array}$ & $\begin{array}{l}\text { En esta dimensión se identifica si los contenidos desarrollados en las clases son conceptos, } \\
\text { procedimientos o actitudes. } \\
\text { Los conceptos se refieren a hechos, principios, leyes, teorías y fenómenos. Los procedimientos } \\
\text { son las habilidades para la investigación. Las actitudes corresponden al conocimiento ético y de } \\
\text { los valores. En una enseñanza constructivista, los contenidos que se trabajan en clase son tanto } \\
\text { conceptuales como procedimentales y actitudinales, a diferencia de una enseñanza tradicional } \\
\text { que da prioridad a la enseñanza de contenidos conceptuales. }\end{array}$ \\
\hline $\begin{array}{l}\text { 2. ¿Cómo enseñan los } \\
\text { docentes del área de } \\
\text { química? }\end{array}$ & $\begin{array}{l}\text { Esta dimensión se basa en los elementos relacionados con las actividades y estrategias desarrolladas } \\
\text { por el docente durante el proceso de enseñanza, basándose en el análisis de los aspectos } \\
\text { relacionados con aquellas actividades educativas que proponen a sus alumnos y su duración, el } \\
\text { nivel de atención que prestan a las ideas previas, las estrategias desarrolladas durante la evaluación } \\
\text { de los alumnos y para propiciar su participación de los alumnos, además de tener en cuenta la } \\
\text { organización de los alumnos en el aula. }\end{array}$ \\
\hline $\begin{array}{l}\text { 3. ¿Qué hacen los } \\
\text { estudiantes durante las } \\
\text { clases de química? }\end{array}$ & $\begin{array}{l}\text { En el análisis de esta dimensión se tienen en cuenta dos elementos: las actividades cognitivas } \\
\text { implicadas en las tareas de los alumnos y la responsabilidad del alumno en el proceso de } \\
\text { enseñanza y aprendizaje. Para un análisis más amplio sobre las prácticas educativas, es importante } \\
\text { tener en cuenta tanto el nivel de dificultad cognitiva de las tareas que los profesores plantean a sus } \\
\text { alumnos, como el grado de responsabilidad y control que ceden a sus alumnos en la realización } \\
\text { de las tareas. Desde el enfoque constructivista, las actividades que los profesores proponen a los } \\
\text { alumnos van más allá de la definición e identificación de conceptos o procedimientos, lo que } \\
\text { se pretende es que los alumnos practiquen el trabajo científico y sean capaces de indagar. Para } \\
\text { conseguir esto, los profesores deben plantear situaciones de aprendizaje a los alumnos que sean } \\
\text { problemas de ciencias auténticos y resulten desafiantes en su complejidad. }\end{array}$ \\
\hline $\begin{array}{l}\text { 4. ¿Cómo interactúan los } \\
\text { docentes y estudiantes } \\
\text { durante las clases de } \\
\text { química? }\end{array}$ & $\begin{array}{l}\text { En esta dimensión, el análisis se centra en la estructura comunicativa que establecen profesores } \\
\text { y alumnos. Se incluyen, dentro de los diálogos iniciados por el profesor, la estructura IRE/F } \\
\text { (iniciación-respuesta-evaluación/feedback) o "diálogo triádico". El análisis de esta dimensión } \\
\text { permiten trazar una escala que va desde las estrategias metodológicas centradas en la materia } \\
\text { (tradicionales/diálogo triádico) a las centradas en el aprendiz (debates, estructuras simétricas). }\end{array}$ \\
\hline
\end{tabular}

Fuente: Blanchar (2017) adaptado de Fernández, et al. (2010). 


\section{Anexo 2. Guía de observación: análisis descriptivo de la práctica pedagógica de la clase de química-Hoja 1 (Continuación)}

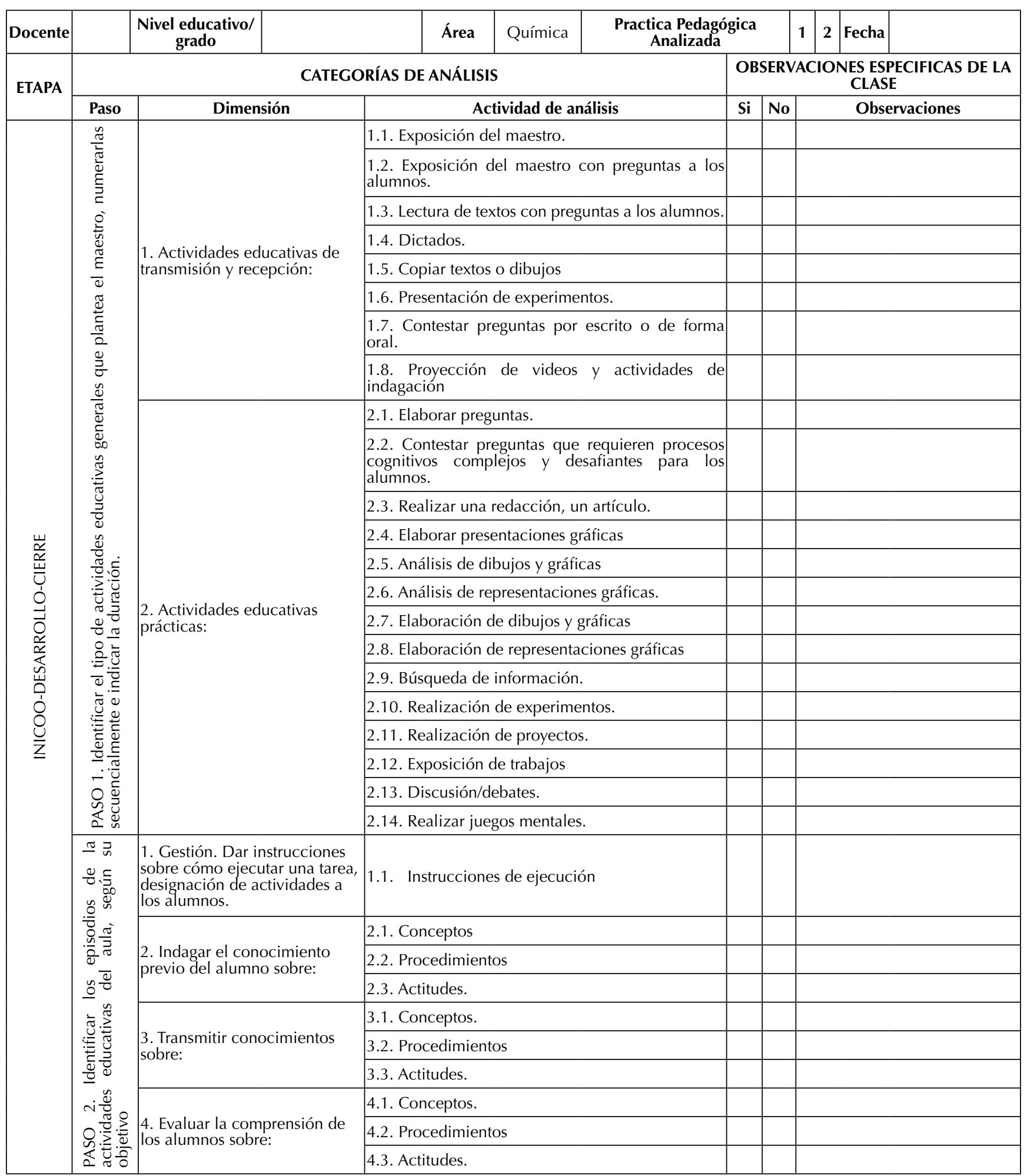

Fuente: Blanchar (2017) adaptado de Fernández, et al. (2010). 


\section{Anexo 2. Guía de observación: análisis descriptivo de la práctica pedagógica de la clase de química-Hoja 2 (Continuación)}

\begin{tabular}{|c|c|c|c|c|c|c|}
\hline \multirow{2}{*}{ ETAPA } & \multicolumn{3}{|c|}{ CATEGORÍAS DE ANÁLISIS } & \multicolumn{3}{|c|}{$\begin{array}{c}\text { OBSERVACIONES ESPECIFICAS } \\
\text { DE LA CLASE }\end{array}$} \\
\hline & Paso & Dimensión & Actividad de análisis & Si & No & Observaciones \\
\hline \multirow{19}{*}{ 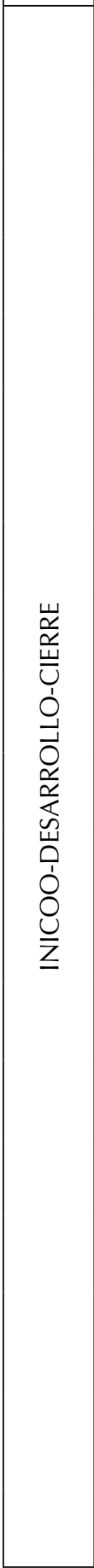 } & \multirow{10}{*}{ 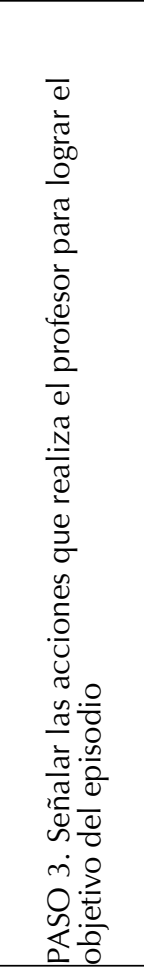 } & $\begin{array}{l}\text { 1. Presentación de } \\
\text { instrucciones sobre la tarea }\end{array}$ & $\begin{array}{l}\text { 1.1 Actividades de orientación sobre las } \\
\text { tareas a realizar }\end{array}$ & & & \\
\hline & & \multirow{5}{*}{$\begin{array}{l}\text { 2. Presentación de } \\
\text { conocimientos }\end{array}$} & $\begin{array}{l}\text { 2.1. Descripción de conceptos/ } \\
\text { procedimientos/actitudes }\end{array}$ & & & \\
\hline & & & $\begin{array}{l}\text { 2.2. Clasificación de las características de } \\
\text { conceptos/procedimientos/actitudes }\end{array}$ & & & \\
\hline & & & $\begin{array}{l}\text { 2.3. Comparación o relación de conceptos/ } \\
\text { procedimientos/actitudes distintos }\end{array}$ & & & \\
\hline & & & $\begin{array}{l}\text { 2.4. Explicación de un fenómeno o proceso } \\
\text { a partir de un modelo conceptual }\end{array}$ & & & \\
\hline & & & $\begin{array}{l}\text { 2.5. Explicación o planificación } \\
\text { procedimental. Analiza las estrategias, } \\
\text { operaciones o decisiones relativas a un } \\
\text { procedimiento o método }\end{array}$ & & & \\
\hline & & \multirow{2}{*}{$\begin{array}{l}\text { 3. Realización de preguntas } \\
\text { cerradas }\end{array}$} & 3.1. Objetivas & & & \\
\hline & & & 3.2. Subjetivas & & & \\
\hline & & \multirow{2}{*}{$\begin{array}{l}\text { 4. Realización de preguntas } \\
\text { abiertas }\end{array}$} & 4.1. Objetivas. & & & \\
\hline & & & 4.2. Subjetivas & & & \\
\hline & \multirow{6}{*}{ 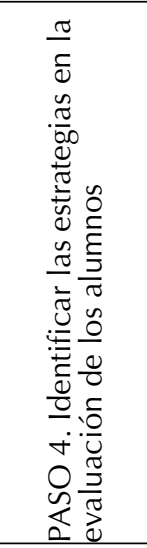 } & 1. Indagar sobre los errores. & 1.1 Tipo de actividad indagativa de errores & & & \\
\hline & & $\begin{array}{l}\text { 2. Crear situaciones de } \\
\text { conflicto cognitivo }\end{array}$ & $\begin{array}{l}2.1 \text { Tipo de situaciones de conflicto } \\
\text { cognitivo }\end{array}$ & & & \\
\hline & & $\begin{array}{l}\text { 3. Proporcionar estrategias } \\
\text { metacognitivas }\end{array}$ & $\begin{array}{l}\text { 3.1 Tipo de estrategias metacognitivas } \\
\text { proporcionadas }\end{array}$ & & & \\
\hline & & $\begin{array}{l}\text { 4. Valorar positivamente el } \\
\text { trabajo de los alumnos }\end{array}$ & $\begin{array}{l}\text { 4.1 Tipo de valoración positiva del trabajo } \\
\text { de los alumnos }\end{array}$ & & & \\
\hline & & $\begin{array}{l}\text { 5. Valorar negativamente el } \\
\text { trabajo de los alumnos }\end{array}$ & $\begin{array}{l}\text { 5.1 Tipo de valoración negativa del trabajo } \\
\text { de los alumnos }\end{array}$ & & & \\
\hline & & $\begin{array}{l}\text { 6. Corregir los errores de los } \\
\text { alumnos }\end{array}$ & $\begin{array}{l}\text { 6.1 Tipo de corrección de errores de los } \\
\text { alumnos y manifestación de la respuesta } \\
\text { correcta }\end{array}$ & & & \\
\hline & \multirow{3}{*}{ 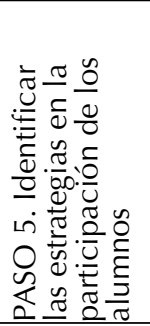 } & $\begin{array}{l}\text { 1. Promover la } \\
\text { participación de los } \\
\text { alumnos. }\end{array}$ & $\begin{array}{l}\text { 1.1 Tipo de actividad de promoción de la } \\
\text { participación de los alumnos }\end{array}$ & & & \\
\hline & & $\begin{array}{l}\text { 2. Promover un clima de } \\
\text { confianza y respeto en el } \\
\text { aula. }\end{array}$ & $\begin{array}{l}\text { 2. Tipo de actividad de promoción de un } \\
\text { clima de confianza y respeto en el aula }\end{array}$ & & & \\
\hline & & 3. Control de la disciplina. & $\begin{array}{l}\text { 3. Tipo de actividad para controlar la } \\
\text { disciplina. }\end{array}$ & & & \\
\hline
\end{tabular}




\begin{tabular}{|c|c|c|c|c|c|c|}
\hline \multirow{2}{*}{ ETAPA } & \multicolumn{3}{|c|}{ CATEGORÍAS DE ANÁLISIS } & \multicolumn{3}{|c|}{$\begin{array}{c}\text { OBSERVACIONES ESPECIFICAS } \\
\text { DE LA CLASE }\end{array}$} \\
\hline & Paso & Dimensión & Actividad de análisis & Si & No & Observaciones \\
\hline \multirow{8}{*}{ 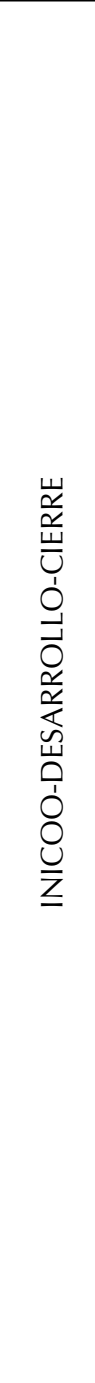 } & \multirow{8}{*}{ 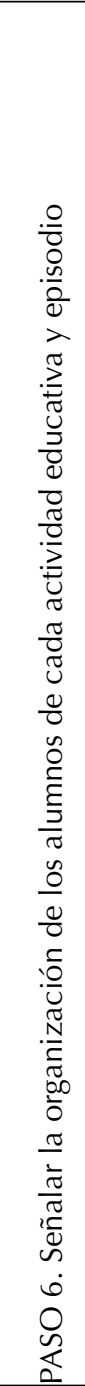 } & 1. Grupo clase. & $\begin{array}{l}\text { 1.1 Actividades de carácter general: Grupo } \\
\text { clase. }\end{array}$ & & & \\
\hline & & 2. Trabajo individual. & 2.1 Actividades de trabajo individual. & & & \\
\hline & & 3. Trabajo en grupos. & 3. Actividades de trabajo en grupos. & & & \\
\hline & & $\begin{array}{l}\text { 4. Trabajo cooperativo en } \\
\text { grupos. }\end{array}$ & $\begin{array}{l}\text { 4. Actividades de trabajo cooperativo en } \\
\text { grupos. }\end{array}$ & & & \\
\hline & & \multirow{2}{*}{$\begin{array}{l}\text { A. Estructuras iniciadas por } \\
\text { el profesor: }\end{array}$} & $\begin{array}{l}\text { A.2. IRE. La secuencia es iniciada por } \\
\text { el profesor (I), a través de una pregunta } \\
\text { (generalmente cerrada). El alumno } \\
\text { responde o realiza la tarea (R) y se produce } \\
\text { un comentario evaluativo (E). El feedback } \\
\text { del profesor es simple: sí/no, bien/mal } \\
\text { o puede que el maestro no diga nada } \\
\text { indicando confirmación. }\end{array}$ & & & \\
\hline & & & $\begin{array}{l}\text { A.3. IRF. Como IRE, pero el profesor } \\
\text { hace preguntas abiertas que requieren } \\
\text { una mayor elaboración por parte de los } \\
\text { alumnos y hay un seguimiento o feedback } \\
\text { del profesor, quien reformula, completa y } \\
\text { no simplemente evalúa como en IRE. }\end{array}$ & & & \\
\hline & & \multirow[b]{2}{*}{$\begin{array}{l}\text { B. Estructuras iniciadas } \\
\text { espontáneamente por el } \\
\text { alumno }\end{array}$} & $\begin{array}{l}\text { B.1. A-P. La secuencia es iniciada } \\
\text { espontáneamente por el alumno que } \\
\text { plantea una pregunta, generalmente } \\
\text { cerrada, al profesor, y éste le contesta. }\end{array}$ & & & \\
\hline & & & $\begin{array}{l}\text { B.2. Estructuras simétricas. La secuencia } \\
\text { comunicativa es iniciada espontáneamente } \\
\text { por los alumnos que aportan información } \\
\text { sobre el tema, por ejemplo en los debates. } \\
\text { B.2.1. A-A. Un alumno se dirige a otro } \\
\text { alumno } \\
\text { B.2.2. A-P. Un alumno se dirige al } \\
\text { maestro. B.2.3. A-Grupo. Un alumno se } \\
\text { dirige al grupo clase. }\end{array}$ & & & \\
\hline
\end{tabular}

Fuente: Blanchar (2017) adaptado de Fernández, et al. (2010). 


\section{Anexo 2. Guía de observación: análisis descriptivo de la práctica pedagógica de la clase de química-Hoja 3 (Continuación)}

\begin{tabular}{|c|c|c|c|c|c|c|}
\hline \multirow[t]{2}{*}{ ETAPA } & \multicolumn{3}{|r|}{ CATEGORIAS DE ANÁLISIS } & \multicolumn{3}{|c|}{$\begin{array}{l}\text { OBSERVACIONES ESPECIFICAS DE } \\
\text { LA CLASE }\end{array}$} \\
\hline & Paso & Dimensión & Actividad de análisis & Si & No & Observaciones \\
\hline \multirow{20}{*}{ 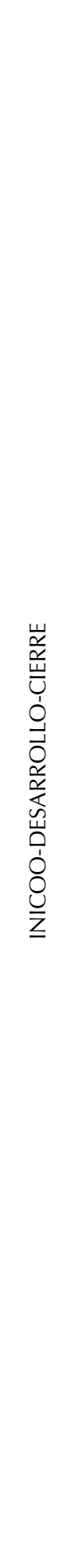 } & \multirow{5}{*}{ 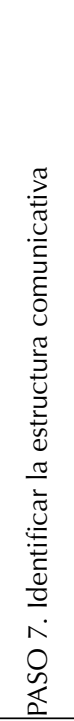 } & \multirow{3}{*}{$\begin{array}{l}\text { A. Estructuras } \\
\text { iniciadas por el } \\
\text { profesor: }\end{array}$} & $\begin{array}{l}\text { A.1. P-A. El profesor se dirige a los alumnos (por ejemplo en la } \\
\text { presentación de conocimientos). }\end{array}$ & & & \\
\hline & & & $\begin{array}{l}\text { A.2. IRE. La secuencia es iniciada por el profesor (I), a través de } \\
\text { una pregunta (generalmente cerrada) o con una indicación sobre } \\
\text { la tarea de aprendizaje. El alumno responde o realiza la tarea (R) y } \\
\text { se produce un comentario evaluativo (E). El feedback del profesor } \\
\text { es simple: sí/no, bien/mal o puede que el maestro no diga nada } \\
\text { indicando confirmación. }\end{array}$ & & & \\
\hline & & & $\begin{array}{l}\text { A.3. IRF. Como IRE, pero el profesor hace preguntas abiertas } \\
\text { que requieren una mayor elaboración por parte de los alumnos } \\
\text { y hay un seguimiento o feedback del profesor, quien reformula, } \\
\text { completa y no simplemente evalúa como en IRE. }\end{array}$ & & & \\
\hline & & \multirow[b]{2}{*}{$\begin{array}{l}\text { B. Estructuras } \\
\text { iniciadas } \\
\text { espontáneamente } \\
\text { por el alumno }\end{array}$} & $\begin{array}{l}\text { B.1. A-P. La secuencia es iniciada espontáneamente por el alumno } \\
\text { gue plantea una pregunta, generalmente cerrada, al profesor, y } \\
\text { éste le contesta. }\end{array}$ & & & \\
\hline & & & $\begin{array}{l}\text { B.2. Estructuras simétricas. La secuencia comunicativa es iniciada } \\
\text { espontáneamente por los alumnos que aportan información sobre } \\
\text { el tema, por ejemplo en los debates. } \\
\text { B.2.1. A-A. Un alumno se dirige a otro alumno } \\
\text { B.2.2. A-P. Un alumno se dirige al maestro. } \\
\text { B.2.3. A-Grupo. Un alumno se dirige al grupo clase. }\end{array}$ & & & \\
\hline & \multirow{15}{*}{ 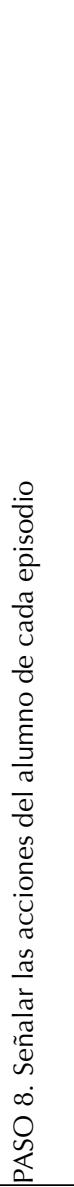 } & \multirow{6}{*}{$\begin{array}{l}\text { A. Acciones } \\
\text { de recepción y } \\
\text { repetición de } \\
\text { conocimientos } \\
\text { derivadas de las } \\
\text { indicaciones del } \\
\text { maestro }\end{array}$} & A.1. Escucha instrucciones sobre la tarea. & & & \\
\hline & & & $\begin{array}{l}\text { A.2. Escucha información sobre conceptos/procedimientos/ } \\
\text { actitudes. }\end{array}$ & & & \\
\hline & & & $\begin{array}{l}\text { A.3. Copia información sobre conceptos/procedimientos/ } \\
\text { actitudes }\end{array}$ & & & \\
\hline & & & A.4. Lee textos escolares en voz alta o de manera silenciosa. & & & \\
\hline & & & $\begin{array}{l}\text { A.5. Expone información sobre conceptos/procedimientos/ } \\
\text { actitudes extraídos textualmente de fuentes como el libro de } \\
\text { texto, Internet, etc. }\end{array}$ & & & \\
\hline & & & $\begin{array}{l}\text { A.6. Contesta preguntas cerradas o abiertas que reproducen } \\
\text { textualmente los conocimientos escolares. }\end{array}$ & & & \\
\hline & & $\begin{array}{l}\text { B. Acciones } \\
\text { manipulativas por } \\
\text { indicaciones del } \\
\text { maestro }\end{array}$ & $\begin{array}{l}\text { B.1. Realiza experimentos, artefactos, trabajo manipulativo en el } \\
\text { laboratorio. }\end{array}$ & & & \\
\hline & & \multirow{8}{*}{$\begin{array}{l}\text { C. Acciones que } \\
\text { implican una } \\
\text { reestructuración } \\
\text { de conocimientos } \\
\text { derivadas de las } \\
\text { indicaciones del } \\
\text { maestro }\end{array}$} & $\begin{array}{l}\text { C.1. Define o representa un concepto/procedimiento/actitud } \\
\text { integrando información de distintas fuentes o con sus propias } \\
\text { palabras. }\end{array}$ & & & \\
\hline & & & $\begin{array}{l}\text { C.2. Relaciona, compara distintos conceptos/procedimientos/ } \\
\text { actitudes. }\end{array}$ & & & \\
\hline & & & C.3. Observa y registra información. & & & \\
\hline & & & $\begin{array}{l}\text { C.4. Selecciona información relevante de datos, identifica } \\
\text { variables, problemas. }\end{array}$ & & & \\
\hline & & & C.5. Elabora conjeturas o hipótesis, realiza predicciones. & & & \\
\hline & & & $\begin{array}{l}\text { C.6. Elabora explicaciones, interpretar datos a partir de modelos, } \\
\text { hechos, principios. }\end{array}$ & & & \\
\hline & & & $\begin{array}{l}\text { C.7. Expresar sus opiniones o lo que sabe sobre un tema a partir } \\
\text { de la experiencia cotidiana. }\end{array}$ & & & \\
\hline & & & $\begin{array}{l}\text { C.8. Evaluar, criticar, opinar sobre su propio trabajo y/o las ideas y } \\
\text { el trabajo de sus compañeros y el de otras personas. }\end{array}$ & & & \\
\hline
\end{tabular}




\begin{tabular}{|c|c|c|c|c|c|c|}
\hline \multirow{2}{*}{ ETAPA } & \multicolumn{3}{|r|}{ CATEGORIAS DE ANÁLISIS } & \multicolumn{3}{|c|}{$\begin{array}{l}\text { OBSERVACIONES ESPECIFICAS DE } \\
\text { LA CLASE }\end{array}$} \\
\hline & Paso & Dimensión & Actividad de análisis & Si & No & Observaciones \\
\hline \multirow{10}{*}{ 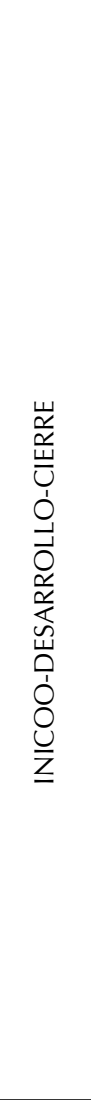 } & \multirow{7}{*}{ 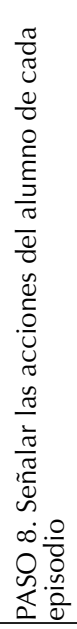 } & \multirow{3}{*}{$\begin{array}{l}\text { D. Acciones que } \\
\text { implican una } \\
\text { reestructuración } \\
\text { de conocimientos } \\
\text { originadas por } \\
\text { iniciativa del } \\
\text { alumno }\end{array}$} & D.1. Realiza preguntas al profesor que tienen que ver con el tema. & & & \\
\hline & & & $\begin{array}{l}\text { D.2. Expresa por propia iniciativa sus opiniones o lo que sabe } \\
\text { sobre el tema. }\end{array}$ & & & \\
\hline & & & $\begin{array}{l}\text { D.3. Evaluar, criticar, opinar sobre su propio trabajo y/o las ideas } \\
\text { y el trabajo de sus compañeros y el de otras personas. }\end{array}$ & & & \\
\hline & & \multirow{4}{*}{$\begin{array}{l}\text { E. Otras acciones } \\
\text { originadas por } \\
\text { iniciativa del } \\
\text { alumno }\end{array}$} & $\begin{array}{l}\text { E.1. Formula preguntas de gestión, pide pautas de trabajo al } \\
\text { profesor. }\end{array}$ & & & \\
\hline & & & E.2. Solicita pautas de evaluación. & & & \\
\hline & & & $\begin{array}{l}\text { E.3. Quejas, críticas, comentarios sobre cuestiones de disciplina } \\
\text { de otros alumnos. }\end{array}$ & & & \\
\hline & & & E.4. Quejas o críticas a las demandas del maestro. & & & \\
\hline & \multirow{3}{*}{ 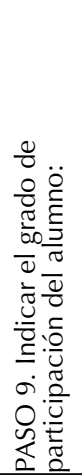 } & 1. Baja. & $\begin{array}{l}1.1 \text { El profesor orienta estrechamente la participación del } \\
\text { alumno en clase; expone información o realiza directamente las } \\
\text { actividades educativas, da indicaciones explícitas a los alumnos, } \\
\text { les realiza preguntas cerradas, frases inacabadas o preguntas } \\
\text { abiertas en las que el alumno tiene que repetir textualmente los } \\
\text { conocimientos escolares. }\end{array}$ & & & \\
\hline & & 2. Media. & $\begin{array}{l}\text { 1.2 El profesor orienta la aportación del alumno con un mayor } \\
\text { margen de libertad, demanda o guía la participación del alumno } \\
\text { mediante indicaciones o preguntas abiertas que demandan al } \\
\text { alumno una reelaboración de los conocimientos escolares. }\end{array}$ & & & \\
\hline & & 3. Alta. & $\begin{array}{l}\text { El alumno es el principal responsable de la acción y de la } \\
\text { información que se hace pública en el aula, realizando } \\
\text { autónomamente las actividades, aportando por propia iniciativa } \\
\text { información nueva al contenido que se elabora o solicitando } \\
\text { ayuda. }\end{array}$ & & & \\
\hline
\end{tabular}

Fuente: Blanchar (2017) adaptado de Fernández, et al. (2010). 